\title{
High Efficiency Dual-Fuel Combustion through Thermochemical Recovery and Diesel Reforming
}

Flavio D.F. Chuahy*, Sage L. Kokjohn

Department of Mechanical Engineering

University of Wisconsin-Madison

Madison, WI 53706 USA

*Corresponding Author (chuahy@wisc.edu)

\begin{abstract}
A computational system optimization was conducted to explore the potential benefits of diesel reforming in dual-fuel combustion strategies. A comprehensive CFD model, validated against syngas $\left(50 / 50 \mathrm{H}_{2} / \mathrm{CO}\right.$ by mole) metal engine experiments, was used to simulate the engine combustion process. The engine CFD solver was coupled with an equilibrium solver for the reformer process and three different reforming processes were investigated: Partial oxidation, steam reforming, and autothermal reforming. A system level approach was used to evaluate the impact of thermochemical recovery of exhaust energy and reformer losses. A design of experiments of simulations was conducted to explore the combustion system design space and a genetic algorithm was used to search the resulting response surface and find the optimal operating conditions. It was found that fuel reforming can increase engine net indicated efficiencies by as much as $9 \%$ due to a shorter combustion duration and reduction in heat transfer losses. The partial oxidation reforming system resulted in the lowest system efficiencies at $44 \%$ due to its exothermic nature, while steam reforming and autothermal reforming were able to achieve over $48 \%$ system efficiency, an improvement in global efficiency of $8 \%$ compared to a diesel baseline due to exhaust heat recovery.
\end{abstract}




\section{Keywords}

Thermochemical recovery, exergy, second law, reformed fuel, syngas, system optimization

\section{Definition of Acronyms}

ATDC - After Top Dead Center

ATR - Autothermal reformer

BDC - Bottom dead center

CA - Crank Angle

CA10 - Crank Angle of 10\% Mass Fraction Burned

CA50 - Crank Angle of 50\% Mass Fraction Burned

$\mathrm{CN}-$ Cetane Number

DI - Direct Injected

DISOI - Direct Injection Start of Injection

DOE - Design of experiments

DPF - Diesel particulate filter

DPI - Diesel pilot ignition

EER - Effective expansion ratio

GA - Genetic algorithm

GIE - Gross Indicated Efficiency

HCCI - Homogeneous Charge Compression Ignition

HRR - Heat Release Rate

IMEP - Indicated Mean Effective Pressure

LH - Latin hypercube

LTC - Low temperature Combustion

LTHR - Low Temperature Heat Release

NIE - Net indicated efficiency

POX - Partial oxidation reformer 
PRF - Primary Reference Fuel

RCCI - Reactivity Controlled Compression Ignition

$\mathrm{SR}$ - Steam reformer

TDC - Top Dead Center

\section{Introduction}

In recent years, a substantial amount of attention has been devoted to advanced, highly premixed combustion strategies (e.g., Reactivity Controlled Compression Ignition (RCCI), Homogeneous Charge Compression Ignition (HCCI), Partially Premixed Combustion (PPC), and Diesel Pilot Ignition (DPI)) [1-4]. These strategies have the potential to achieve high efficiencies while keeping engine out emissions low [5-7] and can be governed by different mechanisms depending on the timing of the fuel injection event [8]. When the injection timing is early in the cycle, chemical kinetics controls combustion phasing and duration [8]. Without direct control over the combustion phasing or duration, practical operation can be challenging using a single fuel. Kokjohn et al. [3] showed that the use of two fuels is a promising method to achieve control of the combustion phasing and duration. In their approach, a low reactivity fuel is premixed with the intake air and a second fuel with higher reactivity is direct injected [9-11]. Combustion phasing is controlled by the ratio of the two fuels and combustion duration is controlled by incylinder stratification of ignition delay. When the injection timing is late in the cycle (i.e., near top dead center), the combustion event becomes directly coupled to the fuel injection event and combustion phasing control is no longer a challenge. In this regime, dual-fuel strategies show emissions and performance benefits by using the premixed fuel to reduce mixing requirements of the direct injected fuel. Accordingly, soot emissions can be reduced and a shorter, more thermodynamically favorable combustion event can be achieved. Consequently, dual-fuel combustion strategies in both the kinetically controlled and mixing limited (or injection coupled) ranges have proven to have benefits over single fuel strategies [12-16]. 
Although dual-fuel results are promising, the use of two fuels presents practical challenges for many applications. To avoid the requirement for two different fuels, "single fuel" strategies have been proposed where gasoline is doped with a cetane improver (2-EHN) [17] and used both as the premixed fuel, in its original composition, and direct injected fuel in its doped version. Although gasoline is the only fuel, there is still the need to handle two different fluids, which introduces application related issues. An alternative approach that enables true single fluid operation is achieved by fuel reforming.

Fuel reforming has been used in the hydrogen production industry for more than 70 years [18]. More recently, reforming processes have been proposed as an in-situ method to recover waste heat in gas turbine and internal combustion (IC) engine applications [19-21]. The concept involves the use of exhaust heat, which is a significant portion of the available energy, to drive on-board endothermic fuel reforming reactions, generating syngas. The syngas is then used as a secondary fuel in the engine, not only enabling the advantages of dual-fuel operation, but also the thermochemical recovery of exhaust energy. From a second law of thermodynamics perspective, the reformed fuel $\left(\mathrm{CO}, \mathrm{H}_{2}\right)$ also presents advantages in the form of reduced combustion exergy destruction, due to the reduced number of product moles and resulting reduction in the entropy of the products. This translates to lower entropy change and higher work production potential per unit exergy of the fuel [22-24]. This approach is the focus of the present study.

Lee and Wimmer [25] were among the first to propose the use of steam reforming to generate syngas as an engine fuel in 1968. Shortly thereafter, Newkirk and Abel [26] were able to implement a gasoline non-catalytic reforming system in what was called the "Boston Reformed Fuel Car" and operate a spark ignition (SI) engine with on demand syngas generation, 
reporting similar engine efficiencies with reduced emissions. Martin [27] further improved the concept by using a catalytic steam reformer in order to reduce reforming temperature demands. Houseman and Cerini [28] reviewed the on-board reforming techniques available at the time and concluded that the implementation of on-board hydrogen generation by partial oxidation and steam reforming was feasible, estimating benefits in vehicle efficiency for a spark ignited engine due to the extension of the engine's lean limit. Sjöström et al [19] were among the first to evaluate the feasibility of using exhaust energy to drive the reforming reactions in a methanol fueled spark ignition engine. They were able to operate with up to $40 \%$ reformed methanol with the exhaust as the only source of energy to drive the reactions.

Jones [20, 29] investigated steam reforming for automotive application in more detail. Simulations and experiments were conducted for $n$-heptane and methanol at various inlet conditions. The results showed that, for both fuels, there were significant improvements in the efficiency. It was assumed for these calculations that the totality of the required energy for reforming would be supplied by the participating exhaust; however, it was later shown that for $\mathrm{n}$ heptane the end of cycle temperatures were not high enough to fully drive the reactions, but could potentially do so for methanol. The author notes that the reaction temperatures required for the suppression of solid carbon formation for $n$-heptane were exceedingly high, of the order of 1000-1100K, suggesting that methanol might be a more suitable fuel due to its low sooting properties. Cracknell et al [30] in an effort to identify suitable fuels for on-board reforming, experimented with a variety of alcohols and hydrocarbons. The results showed a general insensitivity of reformer performance to the base fuel. However, temperature requirements were significantly different, suggesting that for higher efficiency thermochemical recovery, fuels that require lower temperatures would be more suitable. 
More recently Vernon et al. [21] used simulations to explore different energy recovery strategies for fuel reforming operation and concluded that a significant portion of the process heat required for reforming can be provided by the exhaust gases. Posada et al. [31] were one the first to suggest the use of fuel reforming as a technique to simultaneously recover exhaust energy and help control the heat release rates of LTC; however, no attempt was made to quantify the efficiency benefits of having both strategies in place. In more quantitative analyses, Shudo et al. [32] combined methanol reforming to produce DME and syngas in order to help control homogeneous charge compression ignition (HCCI) combustion. A system efficiency of $49 \%$ was reported after heat recovery, a $14 \%$ increase over the base engine results. Chakravarthy et al. [23], expanded on the idea and, through an idealized engine thermodynamic analysis, quantitatively demonstrated the potential of thermochemical recovery. The authors reported a calculated increase of $11 \%$ in system efficiency resulting from the increase in the exergy of the reformed fuel. Tartakovsky [33] further analyzed the potential of methanol and ethanol as base fuels for fuel reforming in a modern spark ignition engine. Results showed improvements in engine efficiency of 13-17\% over a baseline gasoline fueled engine.

Finally, Fennell et al. [36, 37] successfully demonstrated the practical feasibility of the concept in a modern, full scale prototype gasoline direct injection (GDI) engine coupled with a reformer. The substantial amount of work reviewed here shows that on-board reforming is a feasible strategy to increase overall system efficiency, which is fuel flexible and crosscompatible between many combustion strategies. Most of the work has been focused on extending the lean limit of spark ignited engines and a much smaller subset was focused on using reformate products to vary the fuel mixture's reactivity and enhance HCCI control. Quantitative analysis with detailed models capable of predicting the complex effects of syngas co-oxidation 
with different fuels is lacking. The strategy pairs naturally with dual-fuel combustion strategies like RCCI and DPI, a venue that has not been explored. Additionally, a limited number of studies have attempted to quantify the combined effect of the reformer performance and engine performance in the system efficiency, and those that did, made use of simplified engine models, a gap that the current work seeks to address by introducing detailed computational fluid dynamics (CFD) computations of the combustion process.

The present study focuses on three common reforming techniques: partial oxidation reforming (POX), steam reforming (SR), and autothermal reforming (ATR) which combines the two previous approaches. A system level optimization approach is carried out to account for the improvements to the engine efficiency, the thermodynamics of the reforming process and exhaust recuperation. A system layout is proposed for each reforming technique and an optimization is conducted using detailed computational fluid dynamics modelling, validated against experimental data, to explore the combustion design space and find the optimum combined efficiency operating condition for each system. A second law analysis is then performed to compare the multiple systems and evaluate opportunities for further system level improvements.

\section{Material and Methods}

\section{Engine and Laboratory Layout}

The engine used for the validation experiments is a Caterpillar 3401 Single Cylinder Oil Test Engine (SCOTE). Table 1 shows the engine specifications and Figure 1 shows a schematic of the laboratory setup. All gaseous emissions were analyzed with a five-gas Horiba analyzer and smoke was measured with an AVL $415 \mathrm{~S}$ smoke meter. A turbocharger is simulated by pressurizing a closely coupled intake surge tank with compressed air. The original fuel system 
has been replaced by the one specified in Table 2. A port-fuel injection system was installed to provide the premixed fuel.

\section{System Layout}

Figure 2 shows a schematic of each system. For each system, part of the total amount of fuel is directed to the reformer for the conversion process. The syngas leaving the reformer is then directed through a diesel particulate filter (DPF) to collect any solid carbon formed in the reforming process. Any solid carbon formed is removed from the computations resulting in a loss in reformer efficiency. The syngas is then cooled to $40^{\circ} \mathrm{C}$. In the cooling process the water left in the reformate is condensed and can be recycled together with the exhaust water for a closed loop water system. Discussion of the water balance is beyond the scope of the present work, for simplicity the water is considered to be leaving the system at saturation conditions. Part of the intake air is diverted to feed the POX and ATR systems while water is fed into the SR and ATR systems from an external source. For the endothermic processes (SR and ATR), the exhaust is diverted and heat is recovered through another heat exchanger, transferring heat to the input fluids (water and fuel). Any extra heat needed by the endothermic process is then assumed to be supplied by a high grade heat source or burner and added to the reforming process. The energy required for the heat source or burner is added to the input fuel energy in the thermal analysis.

\section{Computational Model}

Computational modeling was performed using an in-house CFD code based on the KIVA family of codes. The code includes improved physical models developed at the University of Wisconsin-Madison's Engine Research Center (ERC) [38]. 
The spray model for this study uses the Lagrangian-Drop and Eulerian-Fluid (LDEF) approach. In order to reduce the grid size dependency of the LDEF spray model and allow accurate spray simulation on a relatively course grid, the Gasjet model of Abani et al. [39] is used to model the relative velocity between the droplets and gas phase in the near nozzle region. The Kelvin Helmholtz- Rayleigh Taylor (KH-RT) model was used to model the spray breakup [40]. The Re-Normalization Group (RNG) k- $\varepsilon$ model was used for turbulent flow calculation [41]. The droplet collision model is based on O'Rourke's model and was expanded by Munnanur [42] to include a more complete list of collision outcomes that considers the effect of bounce, coalescence, and fragmenting and non-fragmenting separations. A wall film sub-model was used to model droplet interaction with the wall [43].

The chemistry calculations were performed by SpeedChem, a sparse analytical jacobian solver coupled to the CFD [44]. The fuel physical properties and kinetics were represented by tetradecane and n-heptane respectively. Co-oxidation of n-heptane and syngas was described by a reduced mechanism with 80 species and 371 reactions that has been validated with experimental ignition delay data, HCCI engine experiments, and direct injection spray combustion data [45].

Soot modelling was performed with a two-step phenomenological soot model based on the approach of Hiroyasu [46]. The rate of change of soot mass, $\dot{M}_{S}$ is determined by the competition between soot formation and oxidation in a CFD cell, and calculated by

$$
\dot{M}_{s}=\dot{M}_{s f}-\dot{M}_{s o}
$$

where $\dot{M}_{s f}$ is the soot formation rate and $\dot{M}_{s o}$ is the soot oxidation rate. The soot formation rate is given by the Arrhenius type expression 


$$
\dot{M}_{s f}=A_{s f} M_{C_{2 H_{2}}} P^{0.5} e^{-\frac{E_{s f}}{R T}},
$$

where $A_{s f}$ and $E_{s f}$ are tuning parameters determined experimentally, $M_{C_{2 H_{2}}}$ is the mass of acetylene and is used as the inception species for soot formation, $P$ is the cell pressure, $T$ is the cell temperature, and $R$ is the ideal gas constant. The soot oxidation rate is discussed in detail in reference [47]. The soot pre-exponential factor and activation energy were calibrated with experimental data as discussed in the model validation section.

NOx is predicted using a 12-reaction NOx mechanism based on the GRI NO mechanism and coupled with the main mechanism chemistry [48]. The grid represents a $51.4^{\circ}$ sector mesh, which includes one nozzle from the injector. The mesh is composed of 21,437 cells at bottom dead center (BDC). The mesh size was selected by performing a grid sensitivity study discussed in the model validation section.

A summary of the models described in this section is illustrated in Figure 3.

\section{Reformer Modelling Approach}

The reformer's product compositions and energy requirements are determined from a gas-solid equilibrium calculation using Cantera [49]. The species chosen for the equilibrium calculation were based on thermodynamic analysis performed by Parmar et al. [50], where the gibbs free energy of a variety of possible product species is compared and the most likely products are used for the equilibrium calculation. The following 8 gas phase species were considered: $\mathrm{H}_{2}, \mathrm{CO}, \mathrm{CO}_{2}, \mathrm{H}_{2} \mathrm{O}, \mathrm{CH}_{4}, \mathrm{~N}_{2}, \mathrm{O}_{2}$ and $\mathrm{C}_{14} \mathrm{H}_{30}$. Solid carbon $(\mathrm{C}(\mathrm{gr}))$ was the sole solid phase species considered. The POX reformer was modelled using constant enthalpy and pressure and the ATR and SR were modelled with constant temperature and pressure to simulate conditions experienced in reformer operation. The input parameters for the simulations were the 
fraction of total fuel diverted to the reformer, reformer temperature (ATR and SR, only), reformer steam to carbon ratio (ATR and SR, only), and reformer air fuel ratio (POX and ATR, only). The reformer operating pressure for the POX and ATR was determined by the engine intake pressure and the SR was operated at atmospheric pressure.

The reformer efficiencies are reported on a lower heating value basis, given by

$$
R_{e f f}=\frac{\sum_{i=1}^{n_{\text {spec }}} m_{i} L H V_{i}}{m_{f} L H V_{f}}
$$

where $m_{i}$ and $L H V_{i}$ are the mass and lower heating value of each species leaving the reformer. $m_{f}$ and $L H V_{f}$ are the mass and lower heating value of the diesel fuel entering the reformer.

Figure 4 shows a comparison of reformer efficiencies calculated for a case with $90 \%$ reformed fuel and $0.12 \mathrm{~g} / \mathrm{cyl}$ total fuel mass. SR shows the highest efficiencies at around 129\%, while POX shows the lowest, with a maximum value of around $87 \%$. The ATR system is an unique combination of the two approaches, and its maximum efficiency is driven by its air fuel ratio. That is, the higher the air fuel ratio, the more dominant the exothermic reactions will be, leading to lower efficiencies, comparable to those of the POX system. At lower air fuel ratios, tending to zero, the ATR performance will approach that of the SR system, where the endothermic reactions are dominant.

To calculate the amount of heat required for the endothermic process after heat recovery, all the thermodynamic states in the system are determined and an energy balance around the reformer is performed. To account for possible phase change during heat recovery, a full equation of state description of the fluids is used. CoolProp [51], an open source thermophysical property library that uses high accuracy Helmholtz energy formulations to describe pure fluid equations of state, is implemented and used to determine the thermodynamic states presented in 
Figure 5. Diesel fuel is represented as dodecane $\left(\mathrm{C}_{12} \mathrm{H}_{26}\right)$. A pinch-point analysis is performed to determine the thermodynamic states at the outlets of the fuel and water heat exchangers (states 10 and 12). The pinch-point is defined as the smallest temperature difference between the cold fluid (fuel and water) and the hot fluid (exhaust). A value of $30 \mathrm{~K}$ is chosen based on typical values utilized in power cycle analysis [52-54]. The value chosen is higher than reported values of $5 \mathrm{~K}$ to $25 \mathrm{~K}$ in order to avoid discussing the tradeoffs between heat exchanger size and performance, as well as the feasibility of such a heat exchanger, which is beyond the scope of the current work. The heat addition required to drive endothermic fuel reforming reactions is

$$
Q_{\text {heat source }}=m_{13} h_{13}+m_{15} h_{15}-m_{10} h_{10}-m_{12} h_{12}-\left(m_{2}-m_{3}\right) h_{2} \text {, }
$$

where $m$ is the mass on a per cycle basis.

We assume that the heat is supplied from a burner; accordingly, the required fuel mass to be added to drive the endothermic process is

$$
m_{f_{u e l} \text { add }}=\frac{Q_{\text {heat source }}}{L H V_{f}} .
$$

The required heat and fuel increases as the steam-to-carbon ratio $(\mathrm{S} / \mathrm{C})$ increases and as the reformed fuel fraction increases due to the increased mass of water and fuel that has to be heated and vaporized, respectively. Additionally, the required heat and fuel increases as the reformer temperature increases. The SR system requires the highest amount of energy and provides an upper bound on energy required. The pure exothermic POX process does not require energy addition. The ATR system depends on the relative importance of its endothermic and exothermic processes, where the heat provided by the exothermic reactions is used by the reformer to 
partially drive its endothermic reactions. Accordingly, an increase in AFR leads to lower energy input requirements; however, as shown before, the reformer efficiency also decreases.

\section{Turbocharger Modelling Approach}

In order to accurately predict the exhaust temperatures necessary for the thermochemical recovery calculations, a simple thermodynamic model is used to calculate exhaust manifold pressure and temperature and then used to determine engine pumping work and post turbo exhaust temperature. The values of temperature and pressure at exhaust valve opening (EVO) are known from the CFD simulation and the temperature and pressure at BDC are calculated assuming an isentropic expansion to bottom dead center. This is followed by an isenthalpic expansion through the exhaust valve to give the enthalpy in the exhaust manifold. This is combined with the work required to drive the compressor, calculated assuming a combined compressor-turbine isentropic efficiency of $40 \%$ and the problem is iteratively solved by varying the exhaust manifold pressure until the entropy balance for the ideal turbine is zero. A backpressure of $12 \mathrm{kPa}$ is applied to the turbocharger to account for pressure drops across the recovery heat exchangers. With the state defined in the exhaust manifold, the post turbine temperature is calculated. Although the simplified model captures the trends in exhaust temperature and pressure correctly, it does not account for heat transfer, consequently, it tends to overestimate the calculated exhaust temperatures. To correct for that, once the optimum has been found, a more accurate one-dimensional gas dynamics model (GT-Power) that includes the effect of heat transfer in pipes and valves is then used to calculate the exhaust manifold conditions and post turbine temperatures.

\section{System Level Efficiency}

To isolate the effect of the combustion process from the reformer, we will discuss both the net indicated efficiency (considering only the engine) and the global efficiency (considering 
the engine, reformer losses, and any energy recovery). The net indicated efficiency is calculated as

$$
N I E==\frac{\int_{-360}^{+360} P d V}{m_{f, D I} L H V_{f}+m_{r e f} L H V_{r e f}},
$$

where $P$ is pressure, $V$ is volume, $m_{f, D I}$ is the mass of the direct-injected fuel, $m_{r e f}$ is the mass of reformed fuel that enters the combustion chamber, and $L H V_{\text {ref }}$ is the lower heating value of the reformed fuel. The global efficiency considers the full system and is calculated as

$$
\eta_{\text {global }}=\frac{\int_{-360}^{+360} P d V}{m_{\text {fuel }_{\text {Total }}} L H V_{f}+m_{\text {fuel }_{\text {add }} L H V_{f}}},
$$

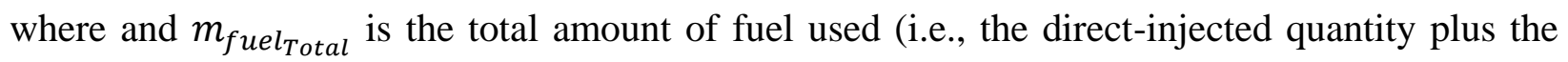
portion entering the reformer) and $m_{\text {fuel }}$ add is the mass of fuel added to drive endothermic reforming reactions.

\section{Second Law Analysis Approach}

A second law analysis presents a different way of looking at the performance of a system through the concept of exergy destruction. The major advantage of second law analysis is that it is able to distinguish between energy flows with the potential to produce work from energy flows that are nearly in equilibrium with the environment and have little potential to produce work. This allows identification of the processes in which the loss of availability is the largest to enable targeted system improvements.

To perform the second law analysis, entropy balances are carried out for each component of the system and the Gouy-Stodola equation is used to determine the exergy destruction 


$$
X_{\text {des }}=T_{0} S_{g e n}
$$

where $T_{0}$ is the dead state temperature and $S_{g e n}$ is the entropy generation. The temperature and pressure of the dead state are $298 \mathrm{~K}$ and $101,325 \mathrm{~Pa}$, respectively. The entropy balance for each component is given by

$$
S_{\text {gen }}=\sum m_{\text {out }} s_{\text {out }}-\sum m_{\text {in }} s_{\text {in }}-\frac{Q}{T_{\text {surf }}}
$$

where $T_{\text {surf }}$ is the temperature at the surface of heat transfer, and it is chosen based on the operating temperature of the component. The values chosen for the analysis are given in the Appendix. It should be noted that the choice of surface temperature affects the entropy generation significantly when comparing values between components, but without actual experiments, the approximations are suitable for the analysis. Finally, the heat can be expressed with the first law of thermodynamics as

$$
Q=\sum m_{\text {out }} h_{\text {out }}-\sum m_{\text {in }} h_{\text {in }}+W
$$

The sign convention is positive for heat into the system, and work out of the system. Finally, the second law efficiency of the system is given by

$$
\eta_{\text {II WORK }}=\frac{\int_{-360}^{+360}\left(P-P_{0}\right) d V}{m_{\text {fuel }_{\text {Total }}} X_{f_{\text {c12h } 26}}+Q_{\text {heat source }}\left(1-\frac{T_{0}}{T_{\text {surf }}}\right)}
$$

where $X_{f_{c 12 h 26}}$ is the chemical exergy of the fuel by unit mass, $Q_{\text {heat source }}$ again is the heat

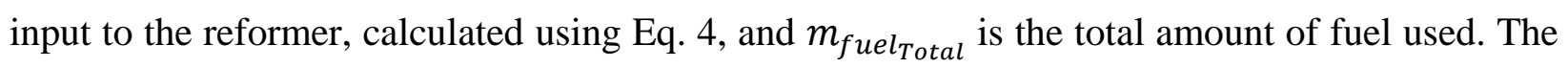
chemical exergy of the fuel is calculated through the following expression for hydrocarbons of the form $C_{x} H_{y} O_{p} S_{q}[55]$ 
$X_{f_{c 12 h 26}}=L H V_{c 12 h 26}\left(1.0401+\frac{0.01728 y}{x}-0.0432 \frac{p}{x}+\frac{0.2196 q}{x}\left(1-\frac{2.0628 y}{x}\right)\right)$.

Analogous to the efficiency equations, the destroyed exergy fraction, the heat exergy fraction and the exhaust exergy fraction are calculated as

$$
\begin{aligned}
& \eta_{I I_{D E S}}=\frac{\sum X_{\text {des }}}{m_{\text {fuel }_{\text {Total }}} X_{f_{\text {c12h } 26}}+Q_{\text {heat source }}\left(1-\frac{T_{0}}{T_{\text {surf }}}\right)}, \\
& \eta_{I_{\text {HEAT }}}=\frac{-Q_{\text {sys }}\left(1-\frac{T_{0}}{T_{\text {surf }}}\right)}{m_{\text {fuel }_{\text {Total }} X_{f_{\text {c12h } 26}}+Q_{\text {heat source }}\left(1-\frac{T_{0}}{T_{\text {surf }}}\right)},} \\
& \eta_{I I_{\text {Exhaust }}}=1-\eta_{I_{\text {WORK }}}-\eta_{I_{\text {IIES }}}-\eta_{I_{\text {HEAT }}},
\end{aligned}
$$

where $Q_{s y s}$ is the amount of heat leaving the boundary of the system.

\section{Optimization Methodology}

The optimization operating conditions are shown in Table 3. The optimization was performed at 9 bar indicated mean effective pressure (IMEP) and $1300 \mathrm{rev} / \mathrm{min}$ without EGR. The goal of the optimization was to maximize the global system efficiency $\left(\eta_{\text {global }}\right)$ while maintaining maximum cylinder pressure rise rates (maxPRR) below $10 \mathrm{bar} / \mathrm{deg}$. No specific constraint was placed on emissions as it is expected that these will be treated with after treatment systems. It should be noted that the values obtained in the optimization study are in the order of magnitude of what is expected a lean NOx aftertreatment can treat, both for conventional diesel and all reforming systems. However, the optimization of combined aftertreatment and engine system performance (i.e. expenditure of aftertreatment additives) is beyond the scope of the current work. Figure 6 shows a flow diagram of the optimization procedure. Latin Hypercube sampling was chosen for the initial DOE generation for the reforming cases, due to its capacity 
to efficiently fill the design space and provide a first approximation for subsequent response surface fitting. A smaller full-factorial DOE was used to determine the point with peak efficiency for conventional diesel combustion due to its reduced number of optimization parameters. The response surface is generated using a non-parametric regression (Component Smoothing Spline Operator-COSSO), and is described in detail by Lin et al. [56]. A genetic algorithm described by Klos [57] is then used to search the calculated response surface for the optimal point. Based on this initial optimum, the design space is restricted and a new DOE is generated. The second response surface is again searched for the optimum value and, by verifying that the optimum point lies inside the DOE interval, the optimization has found its optimal point. The final optimum is then verified with a CFD run. If the design space was too restricted and the optimum point converged to extremes of the DOE range, when feasible, the design space is again expanded and the response surface improved in that region.

Table 4 shows the intervals chosen for the initial DOE. A wide range was chosen for all parameters in order to cover the entire design space. Reformer parameters were chosen based on typical reformer operating conditions reported in the literature and through an initial scoping of reformer efficiencies as shown in Figure 4. The highest reformer operating temperature for the endothermic processes was chosen to be $1123 \mathrm{~K}$ due to material limitation constraints of typical reforming catalysts, and the lowest limited to $1000 \mathrm{~K}$ due to the sharp decrease in reformer efficiency at lower temperatures. The lowest steam-to-carbon ratio is chosen as unity due to the sharp decrease in efficiency for lower values, and the highest at 4 , a value at the higher end of where reformers have been experimentally operated. For the POX reformer, the air fuel ratio ranges from 0.5 to 10 and covers the entire range of operation from the very low efficiencies to the peak efficiency at an AFR of 5.0. The reforming percentage was varied from 0 (conventional 
diesel) to 1 (fully premixed syngas). The intake pressure was set at slightly above atmospheric, at 1.1 bar, up to 2.5 bar. Rail pressure was varied from a low of 400 bar to 1500 bar, a common range of operation for modern common rail systems and the start of injection range was limited to the region where the combustion phasing is directly coupled to the main injection event. Combustion characteristics in this regime are also invariant to the direct injected fuel's physical properties as has been shown in previous work by the authors [58] and allows the extrapolation of the results to other fuels with similar high temperature ignition characteristics.

\section{Computational Model Validation}

\section{Grid Size Sensitivity}

A grid sensitivity study was performed to determine the grid size suitable for use in the optimization. Figure 7 shows the comparison between the cylinder pressures and apparent heat release rates for a $20 \%$ syngas substitution case with increasing grid refinement in the cylinders radial direction and a comparison of soot emissions for 3 different substitution cases with increasing grid refinement. As can be seen, cylinder pressure and heat release rates are not affected by grid resolution even with a total of only 6,000 cells; however, soot emissions are. By carefully analyzing the results, it was decided that a grid with 21,000 cells and a base cell size of $2 \mathrm{~mm}$ gave the best tradeoff between computational time and accuracy. With a base cell size of 2 $\mathrm{mm}$, the cases at $40 \%$ and $60 \%$ syngas substitution show almost no variation in soot with increasing grid resolution, and for $20 \%$ syngas no obvious directional dependence on the grid resolution is observed. That is, even with a cell count as high as 75,000 , the soot magnitude oscillates about a central value.

\section{Engine Performance and Emissions Validation}

All experiments were conducted with a syngas fuel composed of $50 \%$ hydrogen and $50 \%$

carbon monoxide by volume and then compared with the simulated results over a wide variety of 
conditions. Initially, conventional diesel operation over a range of global equivalence ratios was used for the model validation. Then an equivalence ratio of 0.43 was chosen for reformed fuel operation with substitutions up to $60 \%$ by energy, which were used to validate the chemical mechanism's capability of predicting syngas combustion. The SOI timing was maintained for all the cases at $10 \mathrm{deg}$ BTDC and a summary of the test conditions is shown in Table 6 . Figure 8 shows the cylinder pressure and heat release rates for equivalence ratios ranging from 0.36 to 0.58. The model is capable of capturing the cylinder pressure and heat release rate of conventional diesel operation extremely well over a wide range of equivalence ratios. Figure 9 shows the measured and predicted cylinder pressure and heat release rate over a range of syngas substitution quantities. Similar to the neat diesel fuel cases, the simulations are able to adequately capture the combustion characteristics over the range of substitution ratios considered.

Engine out soot emissions were validated against the experimental results. As described previously, the two-step model utilized in this work requires the calibration of two parameters $A_{s f}$ and $E_{s f} . E_{s f}$ was held constant at a value of 12,500. Due to its direct linear relationship with soot formation rate, $A_{s f}$ can be adjusted in a straightforward way to match experimental results. In the current work, $A_{s f}$ was made a function of global equivalence ratio in order to improve the agreement between simulations and experiments. To develop the expression for $A_{s f}$, an initial constant value was used to determine the initial results. The results obtained were then divided by the experimental results and a scaling factor for $A_{s f}$ was devised for each point. $A_{s f}$ was then scaled properly and plotted against equivalence ratio. A quadratic polynomial fit was used to determine the relationship between $A_{s f}$ and engine equivalence ratio. The resulting expression was then used in the simulations 


$$
A_{s f}(\phi)=1130 \phi^{2}-680.8 \phi+153.5 .
$$

The results of this exercise are shown in Figure 10 (a). Excellent agreement is seen for the entire equivalence ratio range. The same $A_{s f}$ expression is applied to the rest of the experimental results, and good agreement is seen for all syngas substitution percentages as well as for different injection pressures as seen on Figure 10 (b).

Engine out NOx was also validated against experimental results. The results are shown in Figure 11. The model is capable of capturing the trends in NOx emissions, however, the magnitude is underestimated. Because the present effort focuses on explaining system level efficiency trends rather than NOx emissions, the agreement is deemed acceptable; however, the reader should keep the NOx validation in-mind when interpreting the results.

\section{Reformer Soot Formation Validation}

The solid carbon formation in reforming processes is a key component that has to be captured in order to accurately predict the reforming process due to its direct impact on efficiency, ultimately driving the optimal reforming operating conditions. The work by Parmar et al. [50] showed a detailed analysis of the solid carbon boundary formation in reforming processes and is used to validate the equilibrium results of the current study. Figure 12 shows that the present method is able to accurately reproduce Parmar's results.

\section{Results and Discussion}

\section{$\underline{\text { Efficiency }}$}

Figure 13 shows global efficiency as a function of maxPRR, maximum in-cylinder soot and engine out NOx emissions for each reforming system, and highlights the optimal results. A wide coverage of the design space was achieved by the design of experiments. The constraint imposed for the maxPRR of $10 \mathrm{bar} / \mathrm{deg}$ had no limiting effect on the optimal solutions. A 
summary of the optimal inputs is shown on Table 6 , and Table 7 shows the optimized outputs for each combustion strategy. Figure 14 shows the net indicated and global efficiency for each optimized case compared to the optimum conventional diesel case. Using reformed fuel combustion increases NIE to over $49 \%$ for all reforming methods, an increase of around $10 \%$ over the diesel baseline. To identify the source of the efficiency improvement, Figure 15 shows the expansion stroke utilization and heat transfer losses as a percentage of the input energy. The expansion stroke utilization is calculated from the heat release rate (HRR) as

$$
\eta_{\text {exp }}=\frac{\sum_{\theta=S O C}^{E O C}\left(H R R(\theta) \frac{V_{B D C}}{V(\theta)}\right)}{C R \sum_{\theta=S O C}^{E O C} H R R(\theta)},
$$

where $\theta$ is the crank angle, SOC is the start of combustion, EOC is the end of combustion, $V_{B D C}$ is the volume at bottom dead center, $V(\theta)$ is the instantaneous volume, and $C R$ is the geometric compression ratio.

From Figure 15, it can be seen that the increase in NIE is explained by a reduction in heat transfer and improved expansion stroke utilization. The expansion stroke utilization is increased due to the shorter combustion duration resulting from the premixed combustion event. The heat transfer losses are reduced by decreasing the direct-injected fuel quantity and keeping high temperature zones away from the piston surface. To illustrate this, Figure 16 shows temperature contours for the diesel case and POX case. The diesel case shows interaction between the high temperature jet and piston bowl surface throughout the combustion event while the POX case shows shorter jet penetration and minimal interaction with the piston bowl surface.

Revisiting Figure 14 shows that the global efficiencies of the SR and ATR cases are higher than the POX case due to energy recovery. For the POX case, the NIE is over $49 \%$. When the reformer losses are considered, the resulting global efficiency decreases to $44.1 \%$. To explain 
the differences in efficiency characteristics, Figure 17 shows the energy flow breakdown for each individual system and gives more insight on the differences between the reforming processes. The reformer losses are comparable for all reforming systems on a percentage of reformer input energy basis; however, for the endothermic systems part of the input energy is being recovered from the exhaust, reducing the total energy required to heat the reactants to reformer operating temperature and drive the reactions. For the POX system, the reformer losses could not be recovered, being responsible for the lowest global efficiencies. SR is shown to be able to reform more fuel, indicated by the lower DI fuel quantity, due to its higher reformer efficiency when compared to ATR, for equivalent reformer losses. The more advanced injection timing required for the higher syngas substitution SR case lead to earlier combustion, thus increasing heat transfer, and offsetting the improvement in EER caused by its shorter combustion duration. SR is able to recover more energy than ATR due to its slightly higher steam-to-carbon ratio, approximately $36 \%$ of the total post turbine exhaust energy, while ATR was able to recover around $29 \%$. Both cases were limited by the exhaust temperature and heat capacitance of the water/fuel streams entering the reformer.

In order to reduce the amount of external energy supplied to drive endothermic reforming reactions, a low reformer temperature and steam-to-carbon ratio would be necessary. However, as is shown in Figure 4 (b), the reformer efficiency decreases substantially when those two conditions are met due to thermodynamic conditions that favor carbon formation. To illustrate this, Figure 18 shows the moles of solid carbon per mole of diesel fuel formed as a function of steam-to-carbon ratio and reformer temperature. As the temperature and steam-to-carbon ratio are decreased, the conditions become more favorable for solid carbon formation. 
In summary, the combination of higher indicated efficiencies and exhaust heat recovery lead to the higher observed global efficiencies for the SR and ATR systems. For the POX systems, the reduction in heat transfer and increase in EER are not enough to overcome reformer losses, leading to comparable, but lower global efficiency than diesel combustion.

\section{Emissions}

Table 7 shows the emissions results for diesel and the three reforming techniques. CO emissions are higher for all reforming techniques due to the presence of $\mathrm{CO}$ in the premixed fuel, which is emitted as unburned fuel due to low local temperatures of crevice and near crevice regions. Between the reforming processes, $\mathrm{CO}$ emissions are lowest for the SR system, at 11 $\mathrm{g} / \mathrm{kgf}$.

NOx emissions are highest for the ATR case at $55 \mathrm{~g} / \mathrm{kgf}$, while diesel and POX were comparable at $35 \mathrm{~g} / \mathrm{kgf}$ and $38 \mathrm{~g} / \mathrm{kgf}$, respectively. SR resulted in the lowest NOx emissions at $14.6 \mathrm{~g} / \mathrm{kgf}$. The differences between the cases can be mainly explained by the operating conditions and its impact on the temperature profiles inside the cylinder. Figure 19 shows the bulk temperature comparison and Figure 20 shows the mass fraction of fuel in the cylinder that is above several defined temperature thresholds as a function of crank angle for the two extreme cases, ATR and SR. It can be seen that despite SR having higher bulk temperatures than ATR, peak temperatures are much lower for the SR case, shown by having no amount of fuel reaching temperatures above $2400 \mathrm{~K}$, while ATR has up to $10 \%$ of the fuel in regions with temperatures higher than $2600 \mathrm{~K}$. This can be explained by the higher substitution ratio and the higher intake pressure of the SR system. More fuel can be steam reformed for similar reforming losses, as detailed in the previous section, leading to lower local equivalence ratios. Additionally, the SR system had the highest optimal intake pressure, which resulted in the lowest global equivalence ratio of all the systems, leading to an overall reduction of peak temperatures. 
Engine out soot emissions are less than $0.01 \mathrm{~g} / \mathrm{kgf}$ for all reformed fuel cases. Accordingly, the results are compared based on the maximum in-cylinder soot. A reduction of over $90 \%$ in maximum in-cylinder soot is observed for all three reforming techniques, as shown in Figure 21, and is attributed to lower mixing requirement of the direct-injected fuel. To illustrate that, Figure 22 shows the mass fraction of fuel inside the cylinder that is above defined equivalence ratio thresholds as a function of time, analogous to the one shown for temperature. It can be observed that, for the conventional diesel case, a larger quantity of the total fuel has higher residence time in regions of high equivalence ratio, leading to higher soot formation than any of the reforming cases. SR presents the largest reduction due to its higher allowed substitution ratio and lower peak temperatures.

\section{Second Law Analysis}

Through the concept of exergy destruction, one can better evaluate where the capacity to produce work is being lost and target those components for system level improvements. Following the approach laid out in the previous section, an entropy balance was performed for the whole system and for each individual component: intercooler, turbocharger, engine, reformer, recovery heat exchanger 1 , recovery heat exchanger 2 , and the syngas cooling heat exchanger.

Figure 23 shows the exergy flow breakdown of the system and the breakdown of the individual contributions of each component to the exergy destruction. The baseline diesel case has a second law efficiency of $39 \%$ with a total exergy destruction of $36.8 \%$. Of the exergy destroyed, $95 \%$ is destroyed in the engine (35\% of the fuels exergy). The remaining exergy destruction results from losses in the turbocharger. For the POX case, the exergy destruction in the engine is decreased to $20.5 \%$ of the fuel's exergy. The reduction in exergy destruction in the engine is caused by multiple beneficial characteristics of reformed fuel combustion. The largest 
source of entropy generation in combustion has been found to be chemical reactions and internal heat transfer $[22,59,60]$. The shorter combustion durations and higher bulk temperatures contribute to the progress of combustion at a higher internal energy state, reducing local temperature gradients and thereby reducing the heat transfer between those zones. Additionally, as was briefly mentioned in the introduction, hydrogen and carbon monoxide have an unique characteristic of yielding a reduced number of molecules as reactions progress, thus lowering the entropy of the products, reducing the entropy change and exergy destruction due to chemistry. However, when the total system exergy destruction is considered, the second law efficiency of POX is lower than the baseline diesel case due to the exergy destroyed in the reformer (13.8\% of the fuels exergy). The SR case shows the highest second law efficiency at $47 \%$. The higher efficiency is due to reductions in the exergy in the exhaust, the exergy associated with heat transfer, and the exergy destroyed. This reduction in exergy destruction for the SR system includes the already discussed benefits of reformed fuel combustion, as well as a reduction in the losses associated with the reformer. While POX reformer losses amount to $13.8 \%$ of the fuel exergy, SR and ATR reformer losses are only $1.2 \%$ and $2.3 \%$, respectively. The ATR case shows a second law efficiency of $45.4 \%$. The decrease in second law efficiency compared to the SR case is primarily due to a reduction in the amount of exhaust exergy recovered (notice that the exergy in the exhaust of the ATR case is $9.7 \%$ while the exergy in the exhaust of the SR case is 6.7\%), slightly less efficient combustion, and higher exergy destruction associated with the reforming process. The latter is due to the partially exothermic nature of the ATR reforming process. Notice that the exergy destruction for SR represents 35.3\% of the input exergy, and 35\% for ATR; however, the absolute value of exergy destruction for ATR is higher than SR. The 
overall input exergy is lower for SR due to a larger part of it being input as heat, which has lower intrinsic exergy.

The exergy destruction contribution breakdown presents the opportunities for system level improvements. It can be seen that for the diesel case most of the exergy is destroyed inside the engine and a smaller portion is destroyed by the turbocharger. Accordingly, improvements must focus on reducing exergy destruction during the combustion process and utilizing a more efficient turbocharger. For the reforming systems, the engine is still responsible for the majority of the exergy destruction, but now the reformer and the heat exchangers in the system contribute up to $40.9 \%$ of the total destruction (POX case), presenting several additional opportunities to improve $2^{\text {nd }}$ law efficiencies. As stated before, due to its exothermic nature, the POX reformer contributes to around $37 \%$ of the total system exergy destruction. Despite that not allowing for exhaust energy recovery, some of the exergy destruction could be reduced by conducting the oxidation process at a higher internal energy state (i.e., using heat from the exhaust or the syngas cooling to pre-heat the air and the fuel entering the reformer); thus, reducing the destruction associated with thermal diffusion processes inside the reformer [61]. This process would, however, increase the outlet temperature of the syngas, potentially reaching temperatures that are practically unfeasible, and the availability destruction reduction is expected to be small.

Reformer losses for ATR and SR are substantially lower than POX and the potential for improvement lies on the exergy destruction due to heat exchanges at fixed temperatures. Figure 23 shows that up to $13.6 \%$ of the total exergy destruction occurs in the three heat exchangers (Syngas HE, Recovery HE1 and Recovery HE2), presenting the possibility of, first, utilizing the heat from syngas cooling, which was not done in the proposed system, and second, potentially 
changing the system layout. Finding the optimal system layout would reduce the overall destruction and maximize energy recovery.

\section{Conclusions}

A full system optimization including three different reforming techniques was performed using comprehensive CFD simulations validated against experimental data. Several conclusions can be drawn from the results of this optimization and in depth analysis of key engine parameters:

- Compared to optimized diesel combustion, all reformed fuel combustion cases show a greater than $4 \%$ absolute increase in net indicated efficiency due to a shorter combustion duration and reduced heat transfer losses.

- By enabling exhaust energy recovery, the endothermic reforming processes were able to achieve the highest global efficiencies. For the exothermic reforming process (POX), losses in the reformer substantially decrease the system level efficiency. Specifically, steam reforming showed an increase in system level efficiency of $3.6 \%$ absolute, autothermal reforming showed an increase in system level efficiency of $3.2 \%$ absolute, and partial oxidation reforming showed a decrease in system level efficiency of $1.0 \%$ absolute. That is, for the POX case, the losses in the reformer outweigh the $4 \%$ improvement in the net indicated efficiency.

- Approximately $36 \%$ of the available exhaust energy was recovered for the SR case, and $29 \%$ was recovered for the ATR case. The exhaust energy recovery was limited by exhaust temperature and heat capacitance of the input mixture to the reformer. Lower reforming temperatures would reduce the energy needed to sustain the endothermic 
process, consequently increasing efficiency; however, carbon formation in the reformer becomes more thermodynamically favorable as the operating temperature is reduced.

- Emissions characteristics are mostly operating condition dependent, however a consistent decrease of over $90 \%$ in in-cylinder peak soot production was seen across all reforming systems, as well as higher $\mathrm{CO}$ emissions associated with the presence of $\mathrm{CO}$ in the premixed fuel located in low temperature crevice regions. NOx emissions were lowest for the SR system due to its higher allowed substitution ratio and resulting lower peak combustion temperatures.

- Exergy destruction for the POX case was substantially higher than SR and ATR due to its exothermic nature, resulting in the lowest $2^{\text {nd }}$ law efficiencies.

- Second law analysis showed that there is potential for improvements in the system layout and utilization of the heat lost during syngas cooling, accounting for up to $13.6 \%$ of system exergy destruction of the endothermic reforming systems.

The current work has shown that fuel reforming combined with DPI dual fuel combustion is capable of increasing the global efficiency of the system over conventional diesel combustion; however, none of the systems were able to achieve efficiencies higher than the NIE. This is a result of limitations in the energy recovery and reformer operating conditions. The amount of energy that could be recovered was limited by the temperature difference between the exhaust flow and the input fluids. Additionally, the reformer temperature, which ultimately drives the amount of heat necessary for the reforming process, was limited by the formation of carbon in the reformer. This suggests that to extend the efficiency improvements presented in the current work, diesel would have to be replaced by a fuel with low solid carbon formation properties and high yield of exergy containing species at low reforming temperatures. 
The current work focused on one mid-load steady state condition. It is expected that the transient performance of the combustion process alone (i.e. without the reformer) be similar to other gaseous dual fuel engines.

Exploring conditions where the exhaust temperature is higher (i.e. higher engine loads) than the reformer operating temperature will result in global efficiencies that equal or surpass the engine only effects to NIE, while conditions where the exhaust temperatures are low, such as lower load conditions, would result in reduced efficiencies due to the increase in external energy supply, down to conditions where conventional diesel operation will become more attractive.

\section{Acknowledgements}

Financial support from the Office of Naval Research contract N000141410695

CEI for providing licenses to Ensight. 


\section{Tables}

Table 1. Engine specifications

\begin{tabular}{|l|c|}
\hline Displacement & 2.44 \\
\hline Bore $[\mathrm{mm}]$ & 137.2 \\
\hline Stroke $[\mathrm{mm}]$ & 165.1 \\
\hline Con. Rod Length [mm] & 261.6 \\
\hline Number of Valves & 4 \\
\hline IVO $\left[{ }^{\circ}\right.$ ATDC] & 335 \\
\hline IVC $\left[{ }^{\circ}\right.$ ATDC] & -143 \\
\hline EVO $\left[{ }^{\circ}\right.$ ATDC] & 130 \\
\hline EVC $\left[{ }^{\circ}\right.$ ATDC] & -355 \\
\hline Swirl Ratio & 0.7 \\
\hline Piston Type & Articulated \\
\hline Piston Profile & Stock Bowl \\
\hline Compression Ratio & $16.1: 1$ (stock) \\
\hline
\end{tabular}

Table 2. Direct-injector specifications

\begin{tabular}{|l|c|}
\hline Nozzle part \# & $\begin{array}{c}\text { Bosch } \\
\text { DLLA148P1347 }\end{array}$ \\
\hline Number of holes & 7 \\
\hline Included Angle [ ${ }^{\circ}$ ] & 148 \\
\hline Hole Diameter [mm] & 0.141 \\
\hline Geometric Area [mm²] & 0.1093 \\
\hline $\begin{array}{l}\text { Nominal hydraulic flow } \\
\left(\mathrm{cm}^{3} \text { per 30s @ 10MPa) }\right.\end{array}$ & 440 \\
\hline
\end{tabular}

Table 3. Summary of operating conditions for simulations

\begin{tabular}{|l|c|}
\hline & Value \\
\hline IMEPg [bar] & $\sim 9$ \\
\hline Intake Temperature [K] & 350 \\
\hline Intake Pressure [bar] & Variable \\
\hline EGR [\%] - Residuals & 4 \\
\hline Equivalence Ratio & Variable \\
\hline
\end{tabular}


Table 4. Initial DOE ranges for LH sampling

\begin{tabular}{|l|c|c|c|c|}
\hline & Range Diesel & Range POX & Range SR & Range ATR \\
\hline Reformer AFR & N/A & 0.5 to 10 & N/A & 0.5 to 10 \\
\hline Fraction of Fuel to Reformer & N/A & 0 to 1 & 0 to 1 & 0 to 1 \\
\hline Steam to Carbon Ratio & N/A & N/A & $1-4$ & $1-4$ \\
\hline Reformer Temperature [K] & N/A & N/A & $1000-1123$ & $1000-1123$ \\
\hline Boost Pressure [bar] & $1.1-2.5$ & $1.1-2.5$ & $1.1-2.5$ & $1.1-2.5$ \\
\hline Diesel SOI [ ${ }^{\circ}$ ATDC] & -25 to 0 & -25 to 0 & -25 to 0 & -25 to 0 \\
\hline Common Rail Inj. Pressure [bar] & 500 to 1500 & 500 to 1500 & 400 to 1500 & 400 to 1500 \\
\hline
\end{tabular}

Table 5. Summary of engine validation experiments

\begin{tabular}{|l|c|c|}
\hline & Diesel & Syngas \\
\hline Engine Speed [rev/min] & 1300 & 1300 \\
\hline SOI [ ${ }^{\circ}$ ATDC] & -10 & -10 \\
\hline Equivalence Ratio [-] & $0.36-0.43-0.50-0.58$ & 0.43 \\
\hline Substitution Ratio [\% Energy] & $0 \%$ & $20 \%-40 \%-60 \%$ \\
\hline Fuel Energy [J] & $\sim 5100$ & $\sim 5100$ \\
\hline
\end{tabular}

Table 6. Summary of input parameters for optimized points

\begin{tabular}{|l|c|c|c|c|}
\hline & Diesel & POX & SR & ATR \\
\hline SOI [ ${ }^{\circ}$ ATDC] & -10 & -14.5 & -24 & -12 \\
\hline Rail Pressure [bar] & 1000 & 510 & 525 & 500 \\
\hline Intake Pressure [bar] & 1.5 & 1.5 & 1.6 & 1.55 \\
\hline Premixed Fuel [\% by Energy] & 0 & 83.2 & 96.8 & 87.2 \\
\hline Reformer AFR [-] & N/A & 5.05 & N/A & 0.5 \\
\hline $\begin{array}{l}\text { Mass fraction of Fuel Reformed } \\
{[-]}\end{array}$ & N/A & 0.85 & 0.96 & 0.85 \\
\hline Reformer Temperature [K] & N/A & N/A & 1050 & 1050 \\
\hline Steam-to-Carbon Ratio [-] & N/A & N/A & 1.2 & 1 \\
\hline
\end{tabular}


Table 7. Summary of output parameters for optimized points

\begin{tabular}{|l|c|c|c|c|}
\hline & Diesel & POX & SR & ATR \\
\hline GIE [\%] & 45.5 & 49.7 & 50.2 & 50.1 \\
\hline NIE [\%] & 45.1 & 49.2 & 49.7 & 49.6 \\
\hline Global Efficiency [\%] & 45.1 & 44.1 & 48.7 & 48.3 \\
\hline Maximum Soot [g/kgf] & 0.99 & 0.1 & 0 & 0.06 \\
\hline Engine out Soot [g/kgf] & 0.07 & 0 & 0 & 0 \\
\hline EICO [g/kgf] & 6.3 & 24 & 11 & 19.7 \\
\hline EINOx [g/kgf] & 35 & 38 & 14.6 & 55 \\
\hline Reformer Efficiency [\%] & 0 & 87.7 & 128 & 121 \\
\hline Combustion Duration [deg] & 30.5 & 20 & 13 & 18 \\
\hline CA50 [ ${ }^{\circ}$ ATDC] & 12 & 2.5 & 1.5 & 3.5 \\
\hline Maximum PRR [bar/deg] & 5 & 8.2 & 9.2 & 7.2 \\
\hline
\end{tabular}


Figures

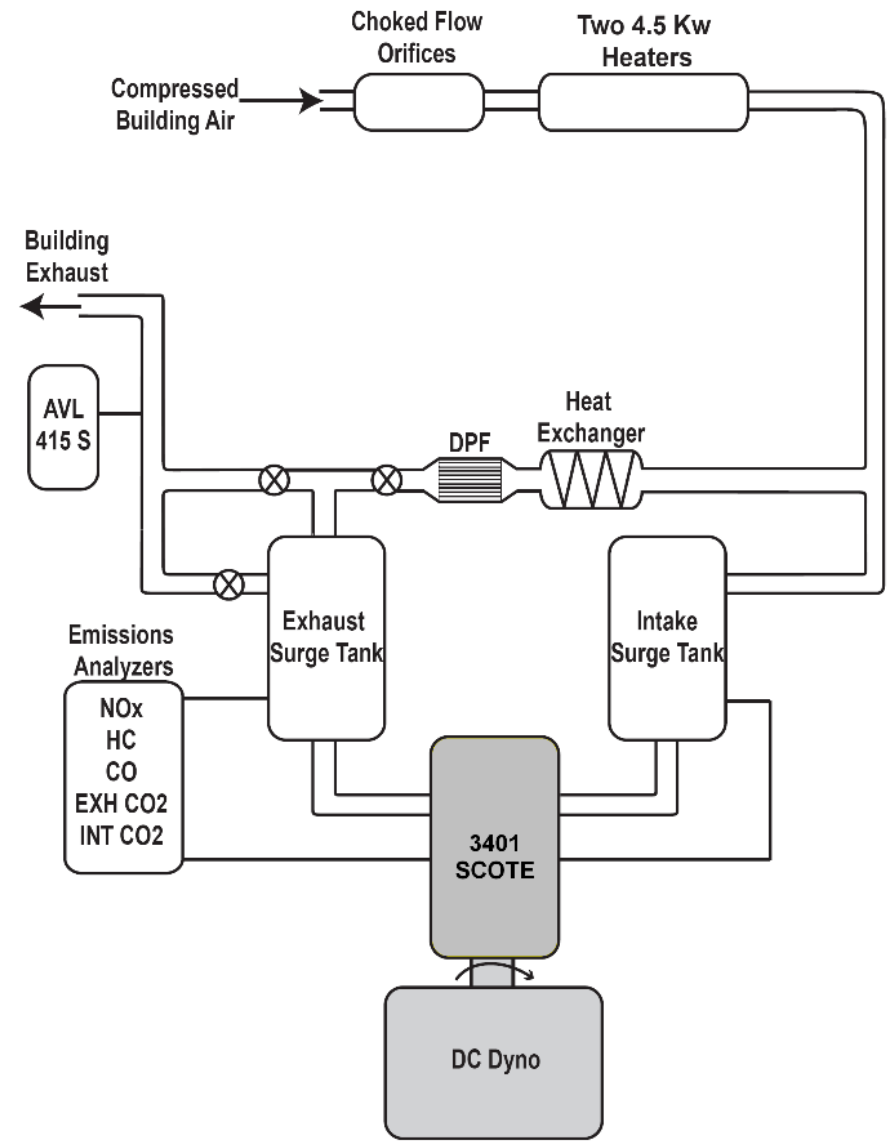

Figure 1. Schematic of laboratory apparatus. 

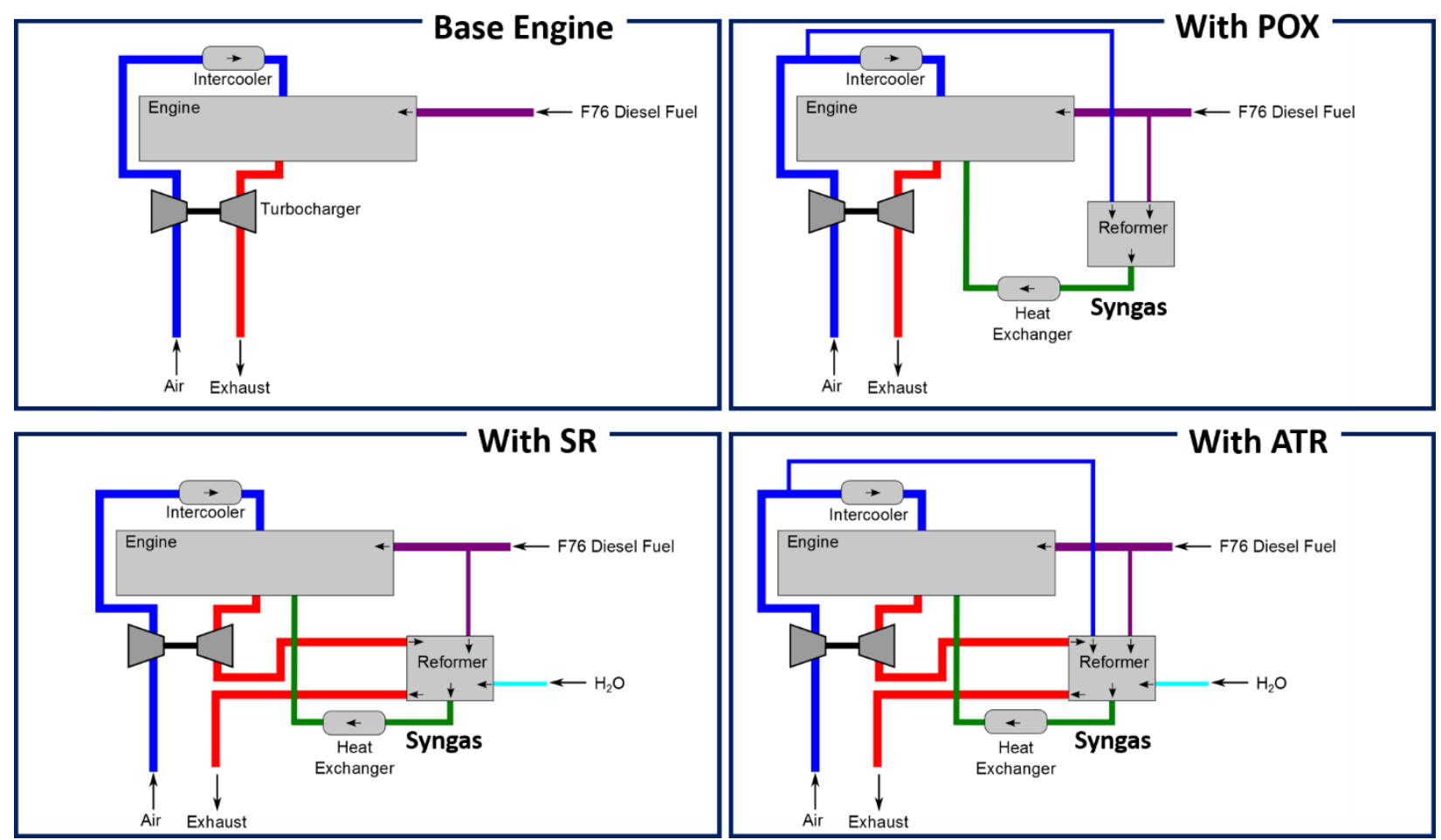

Figure 2. Schematic representation of system layout for different reforming techniques 


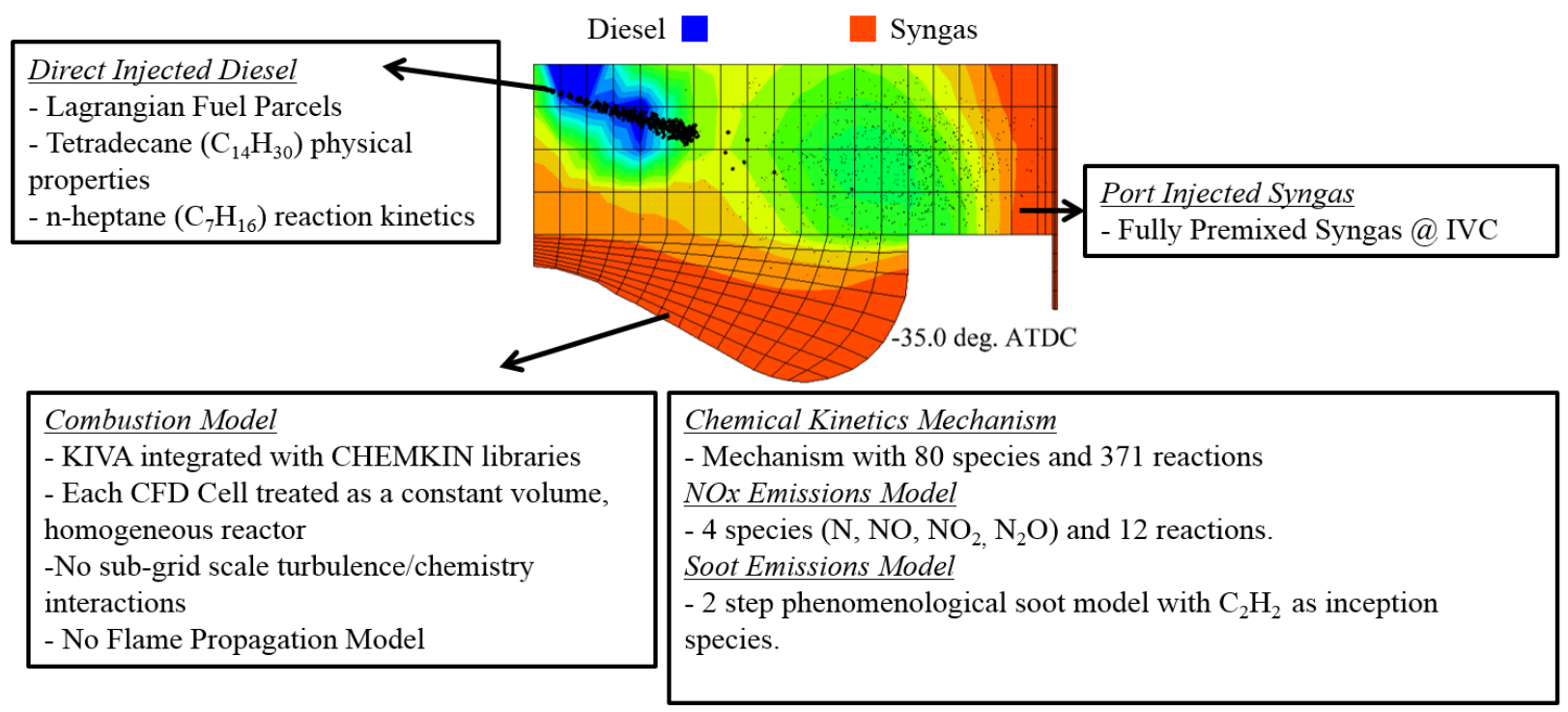

Figure 3. Summary of computational models used in the combustion calculations.

Adapted from [62]. 


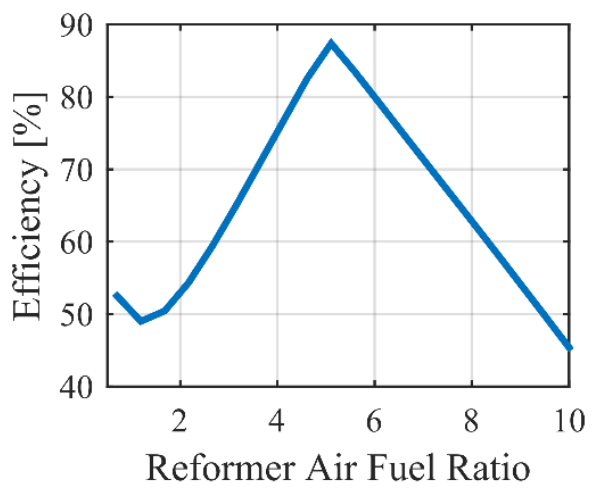

(a)

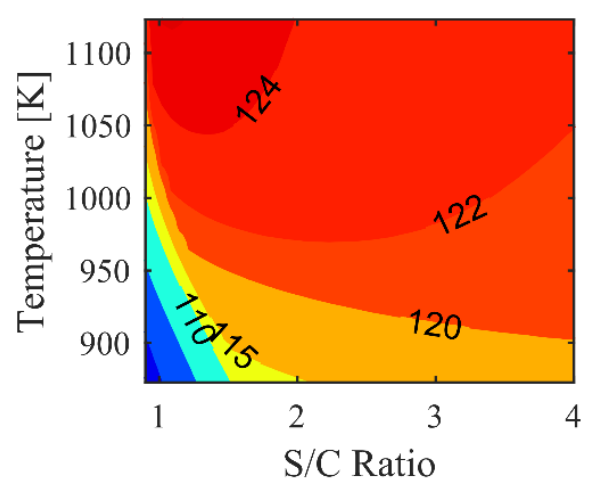

(c)

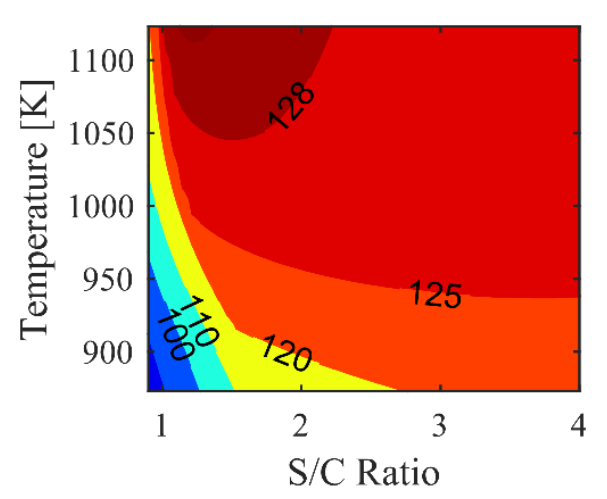

(b)

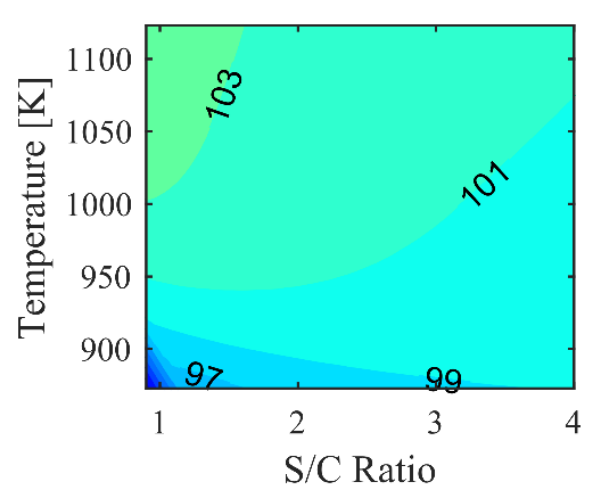

(d)

Figure 4. Reformer efficiency. (a) POX efficiency as function of AFR (b) SR reformer efficiency contour as a function of $\mathrm{S} / \mathrm{C}$ and temperature (c) ATR reformer efficiency contour as a function of $\mathrm{S} / \mathrm{C}$ and temperature for $\mathrm{AFR}=0.5$, and (d) ATR reformer efficiency contour as a function of $\mathrm{S} / \mathrm{C}$ and temperature for $\mathrm{AFR}=3$ 


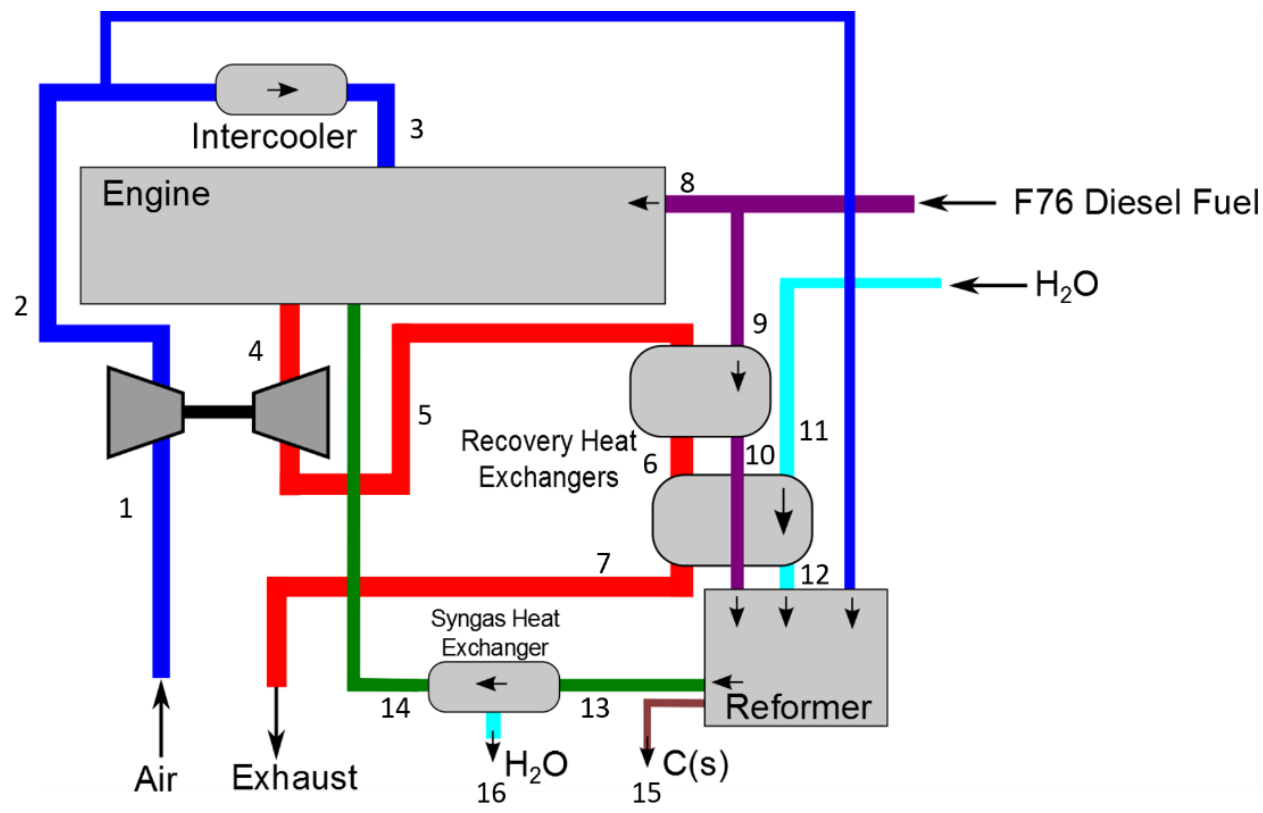

Figure 5. Thermodynamic states of the systems 


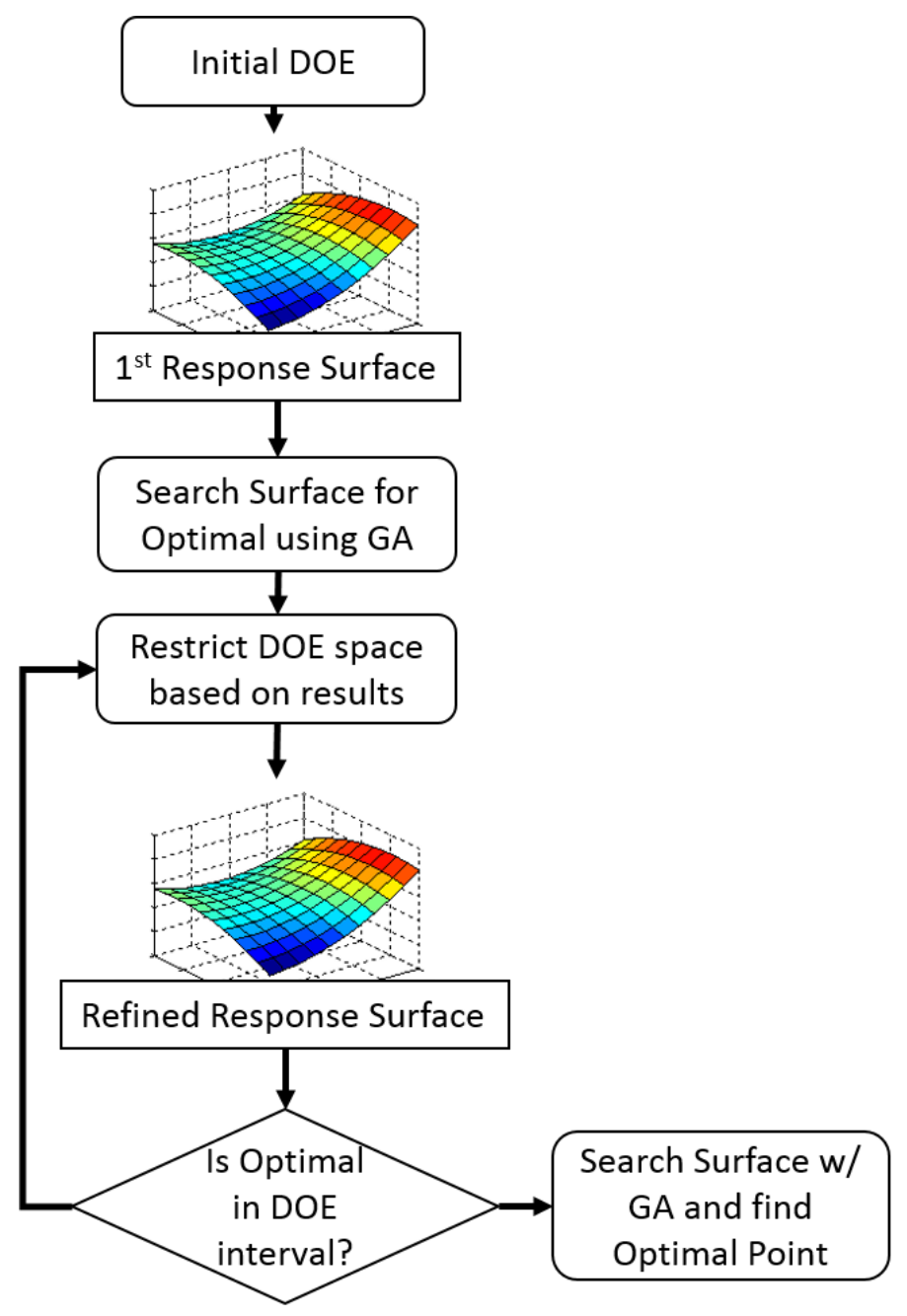

Figure 6. Flow diagram of optimization procedure 


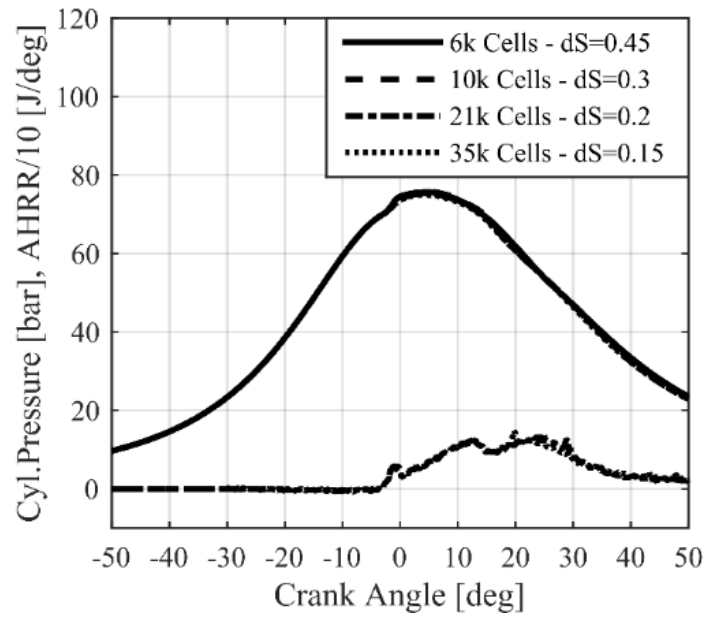

(a)

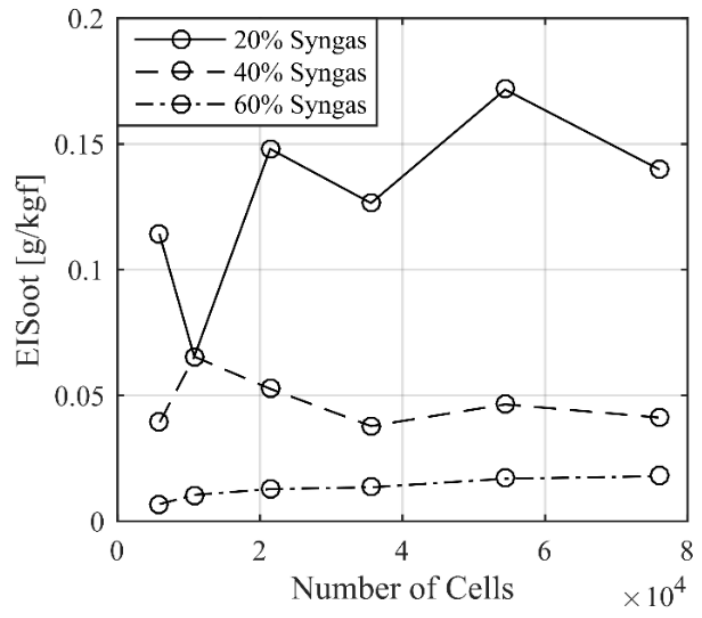

(b)

Figure 7. (a) Comparison of pressure and heat release rate with increasing grid refinement for a $20 \%$ syngas substitution case, (b) grid convergence of soot emissions for three syngas substitution levels. 

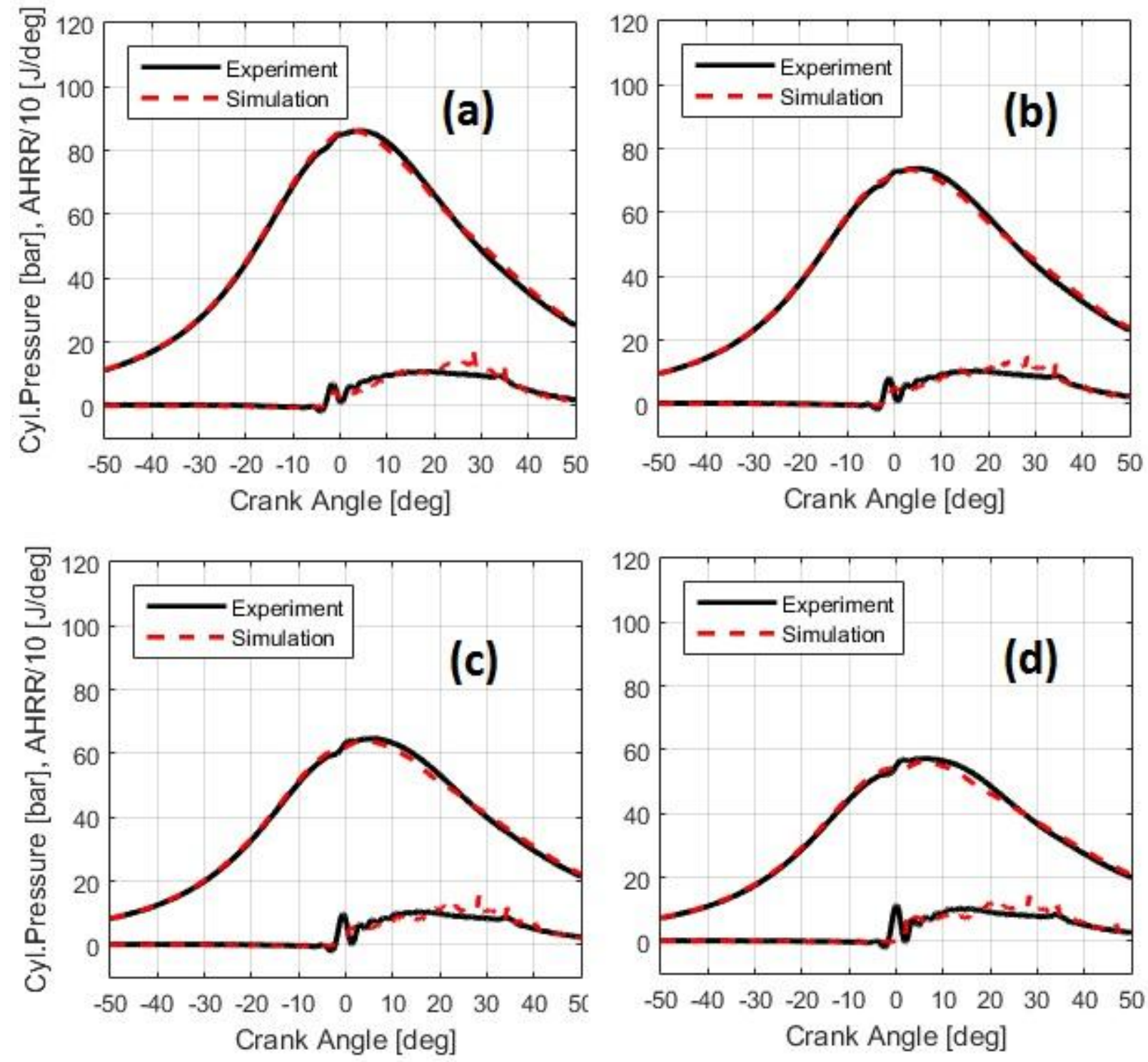

Figure 8. Validation for conventional diesel operation with varying equivalence ratios. (a) phi $=0.36$ (b) phi $=0.43$ (c) phi $=0.50$ (d) phi $=0.58$ 

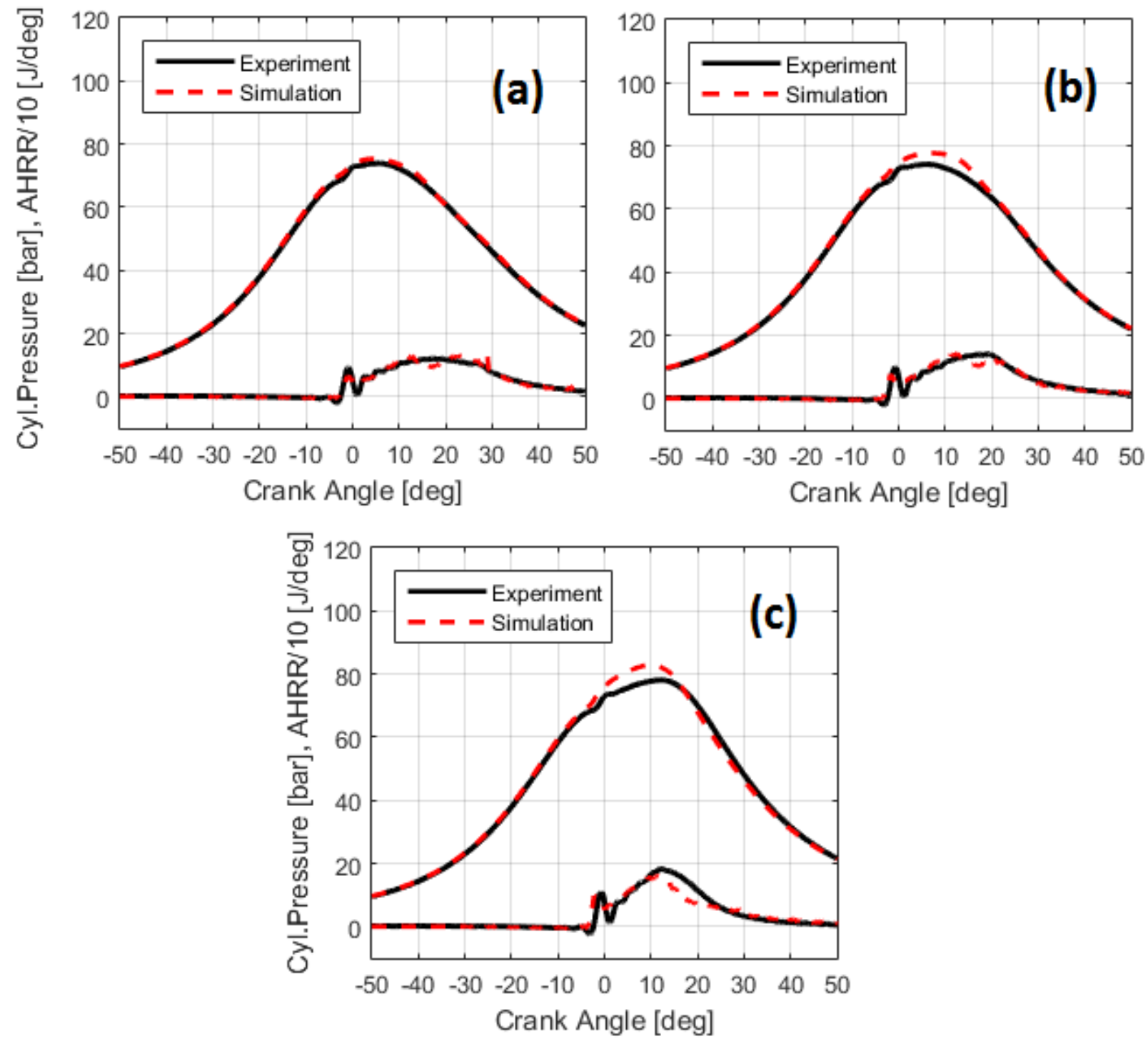

Figure 9. Validation for dual fuel diesel and $50 / 50 \mathrm{H} / \mathrm{CO}$ syngas with varying substitution ratios, (a) syngas $=20 \%$ (b) syngas $=40 \%$ (c) syngas $=60 \%$. 


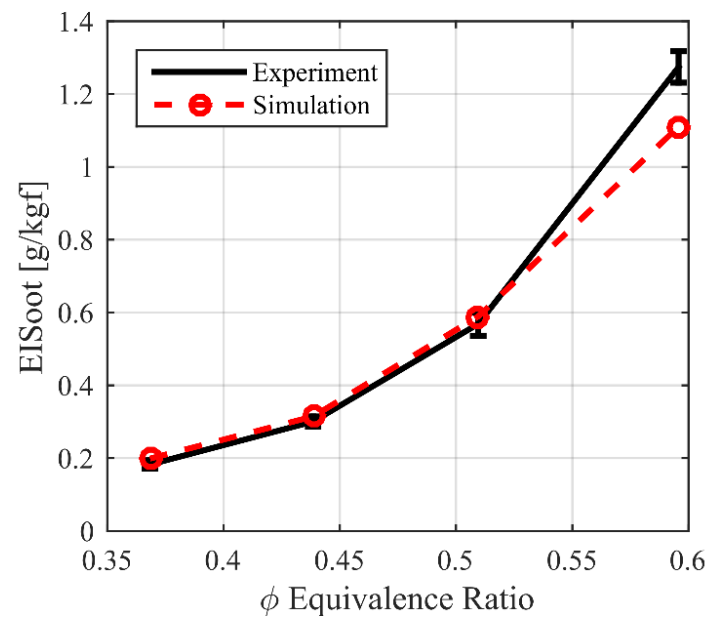

(a)

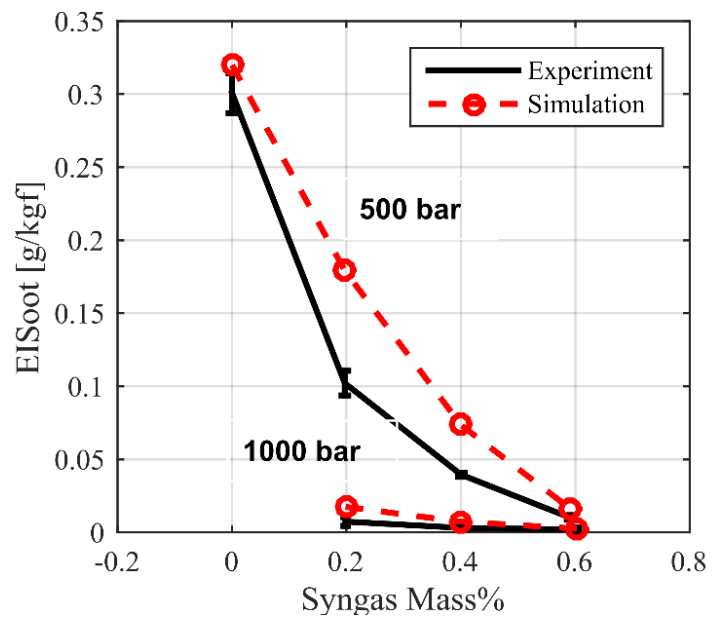

(b)

Figure 10. (a) Comparison of soot emissions between experiment and simulation for varying equivalence ratios. (b) Comparison of soot emissions between experiments and simulation for varying syngas percentage and injection pressures of 500 bar and 1000 bar.

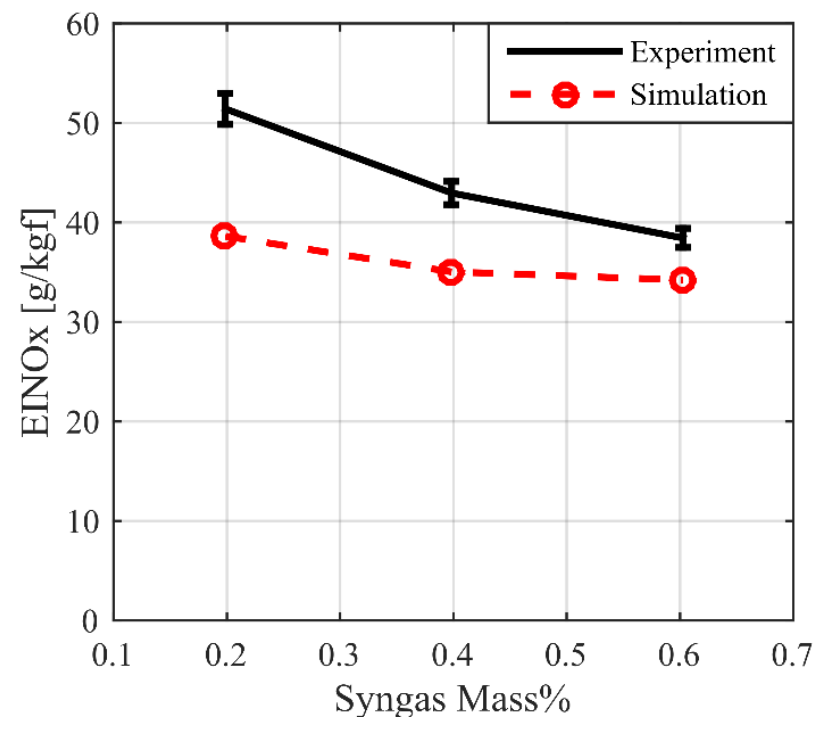

Figure 11. Comparison of NOx emissions between experiment and simulation for varying syngas percentages. 


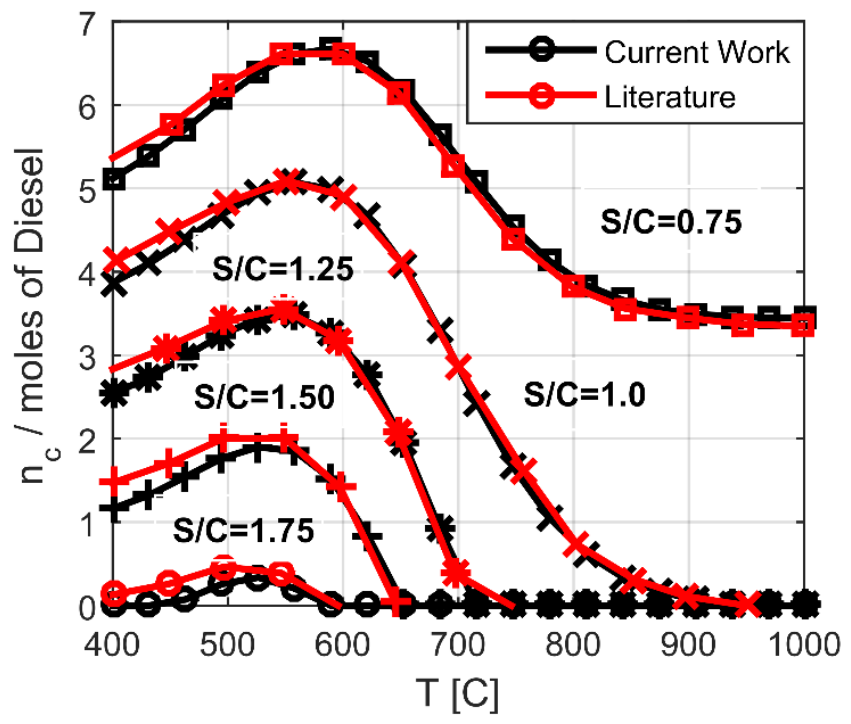

Figure 12. Comparison of solid carbon formation boundary for steam reforming between previous [50] and current work for various temperatures and steam-to-carbon ratios at 1 atm operating pressure. 

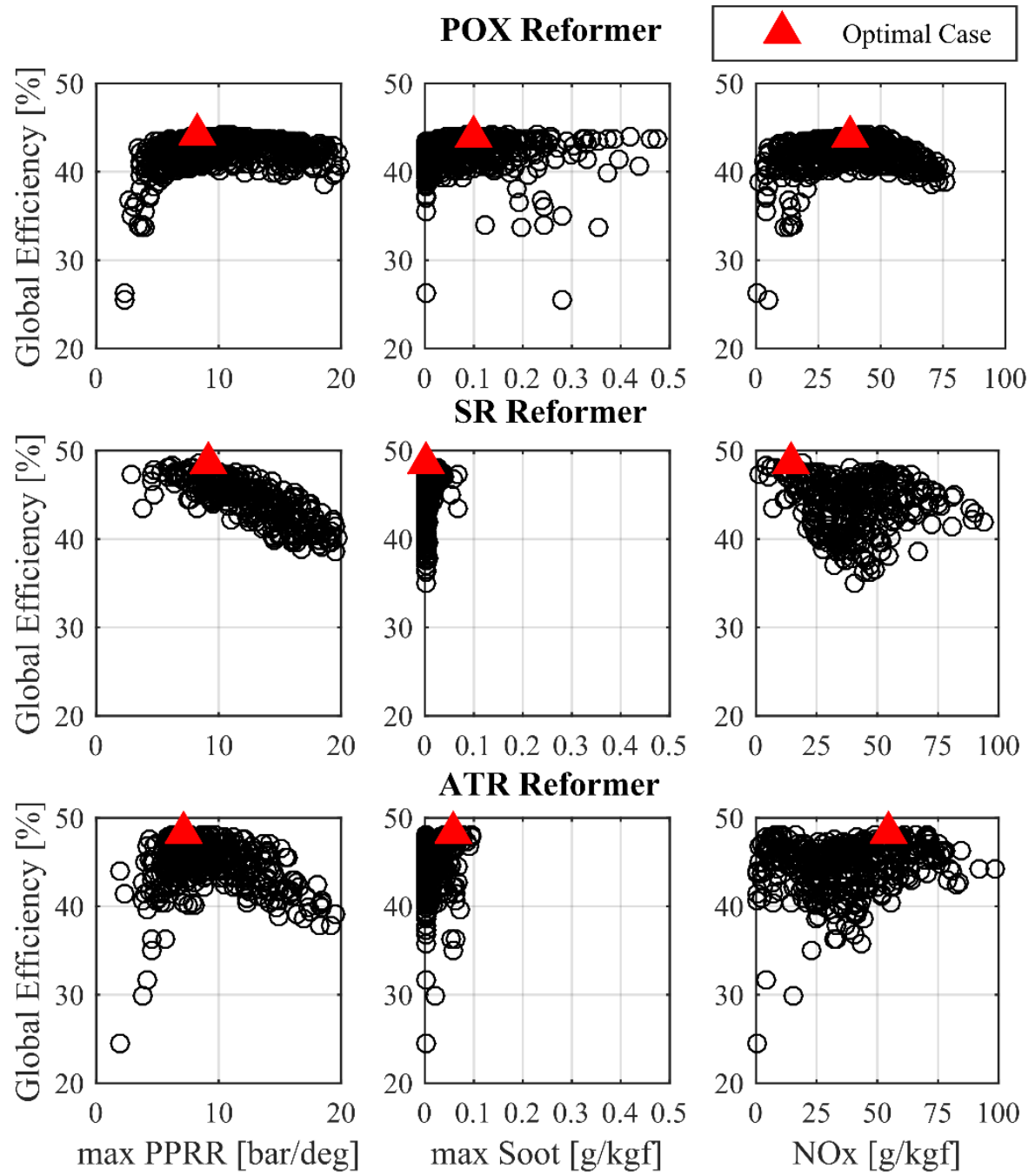

Figure 13. Global efficiency as a function of important design parameters for design of experiments computations and optimal points. 


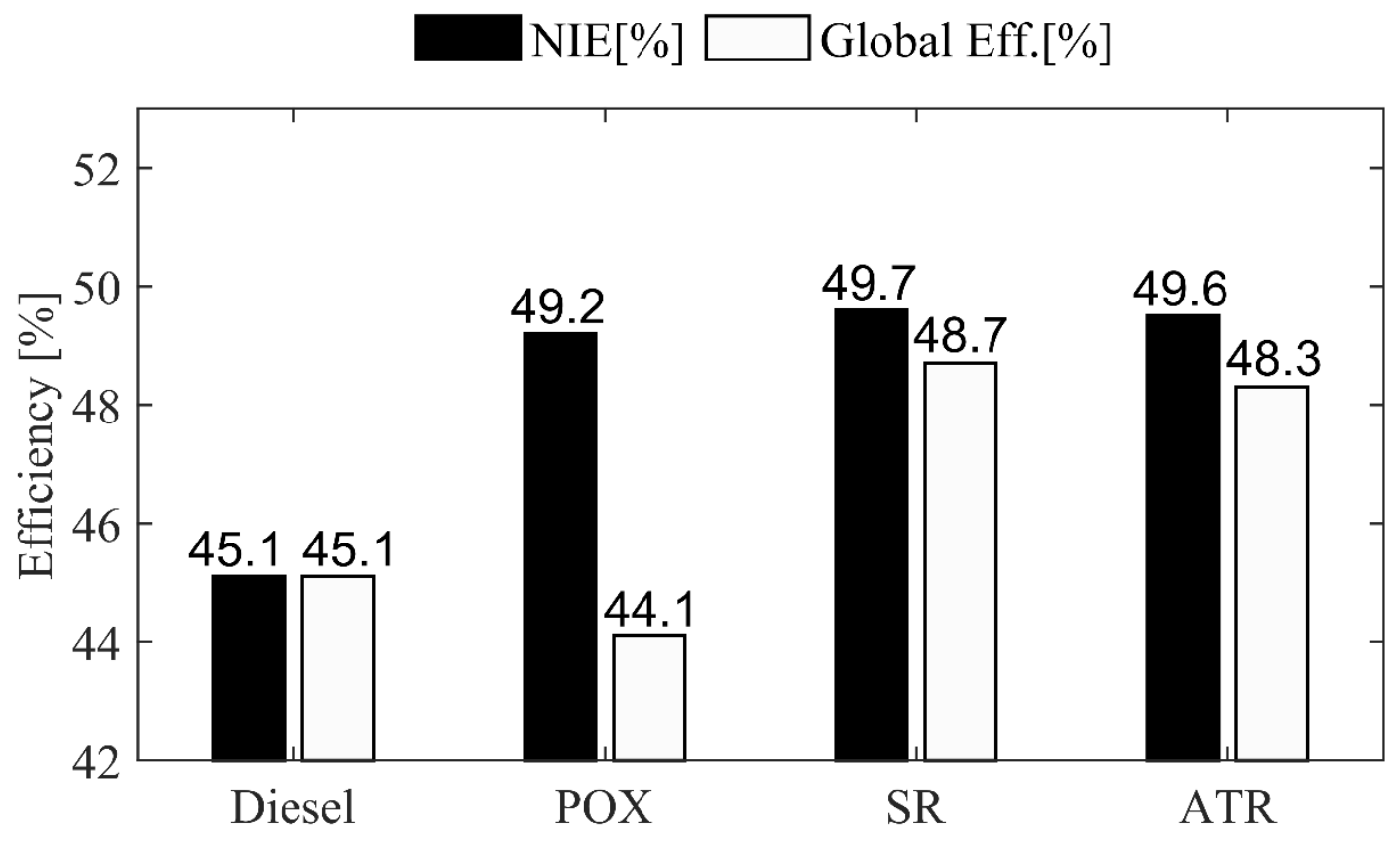

Figure 14. NIE and Global Efficiencies for each optimized case. 


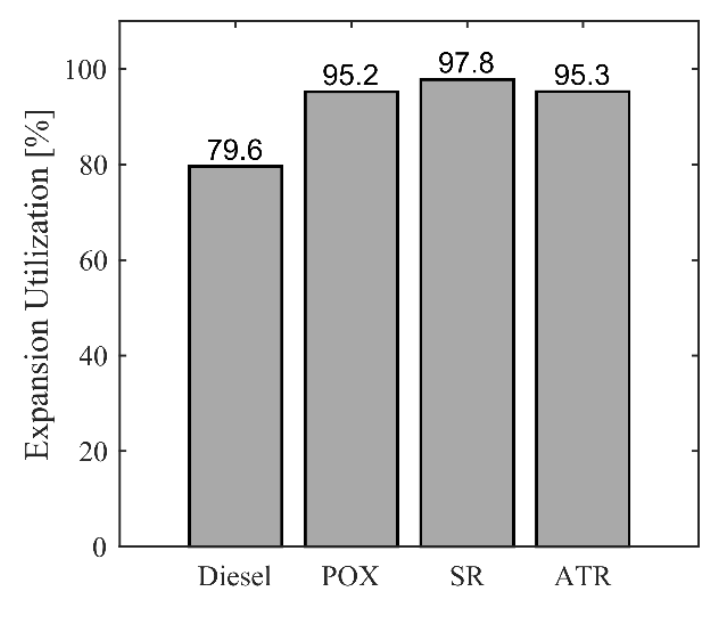

(a)

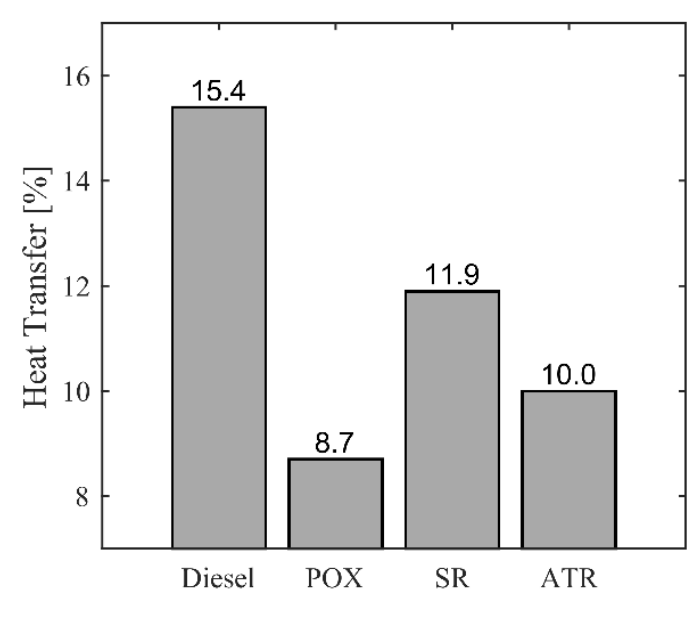

(b)

Figure 15. (a) Expansion stroke utilization and (b) heat transfer as percentage of input energy. 

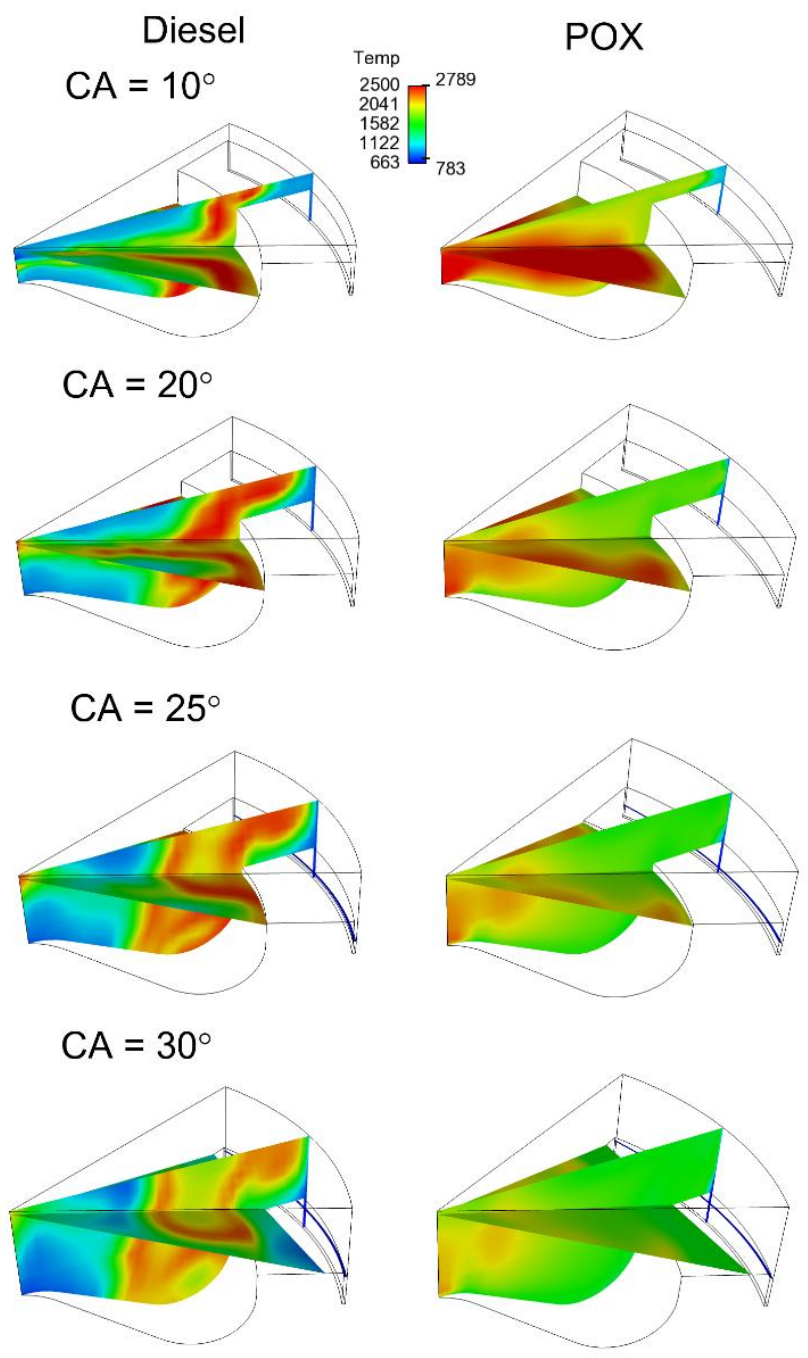

Figure 16. In cylinder temperature contours for diesel baseline and optimum POX point. 


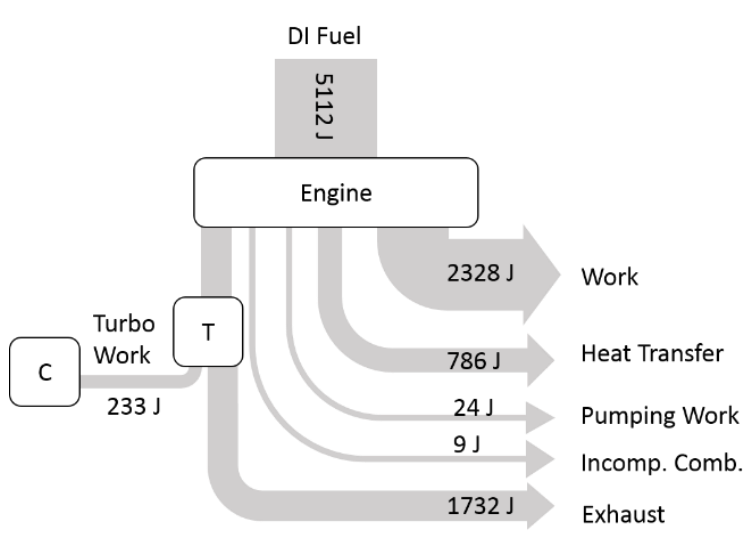

(a)

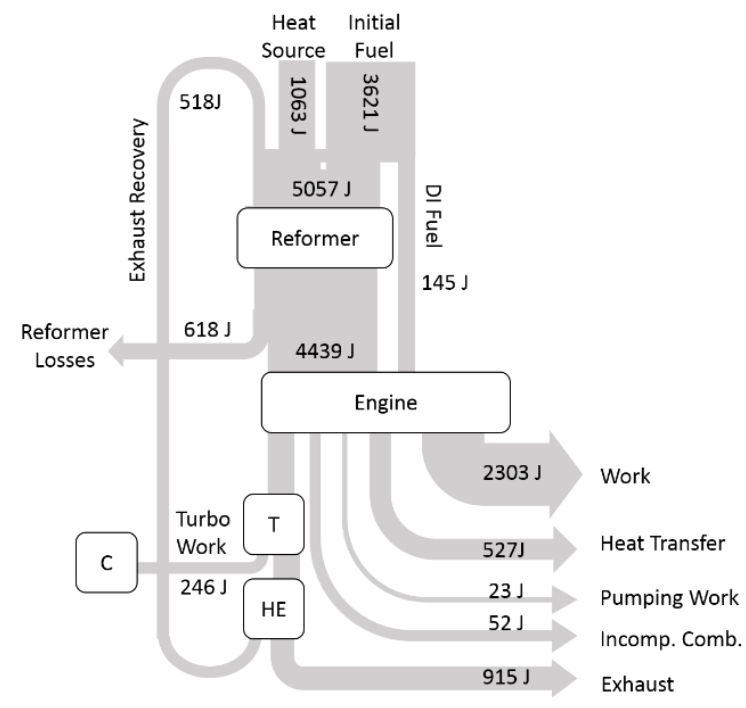

(c)

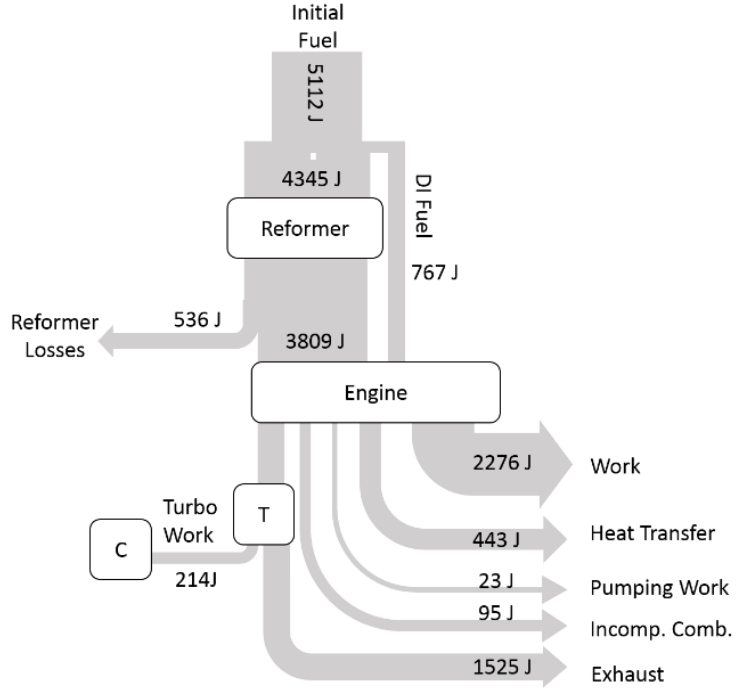

(b)

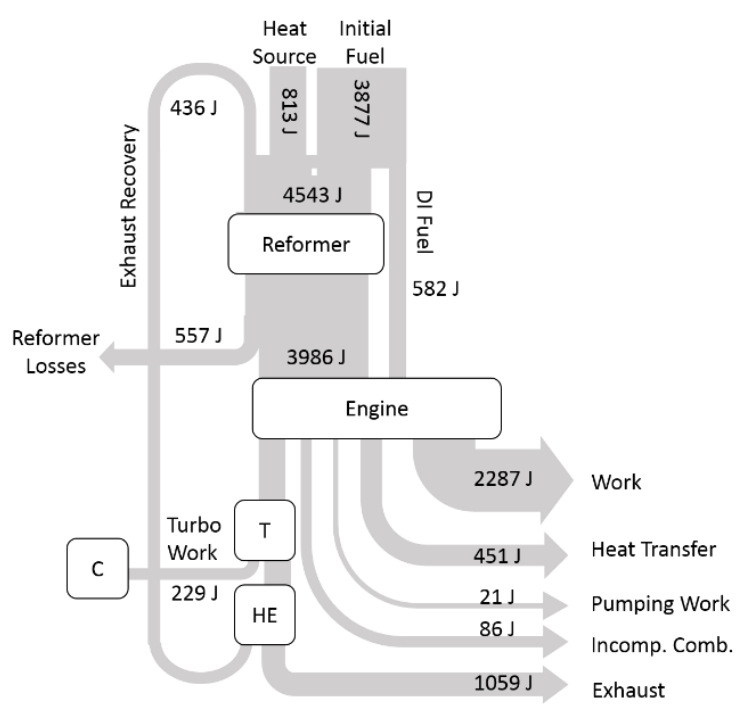

(d)

Figure 17. (a) Diesel energy flow diagram, (b) POX energy flow diagram, (c) SR energy flow diagram, and (d) ATR energy flow diagram 


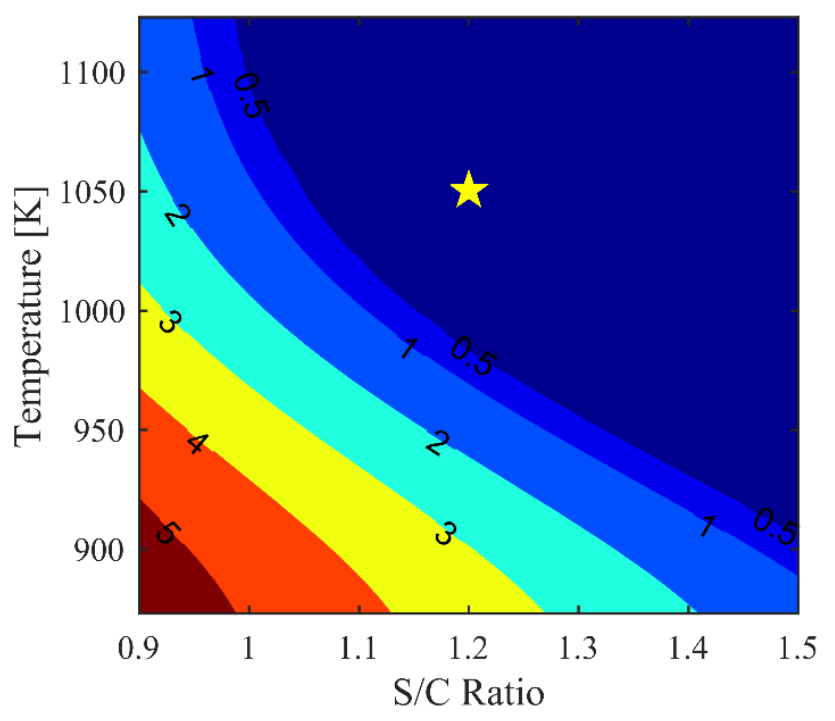

Figure 18. Carbon formation boundary showing contours of moles of carbon per moles of diesel fuel. The star represents the optimal point for found for the steam reforming system. 


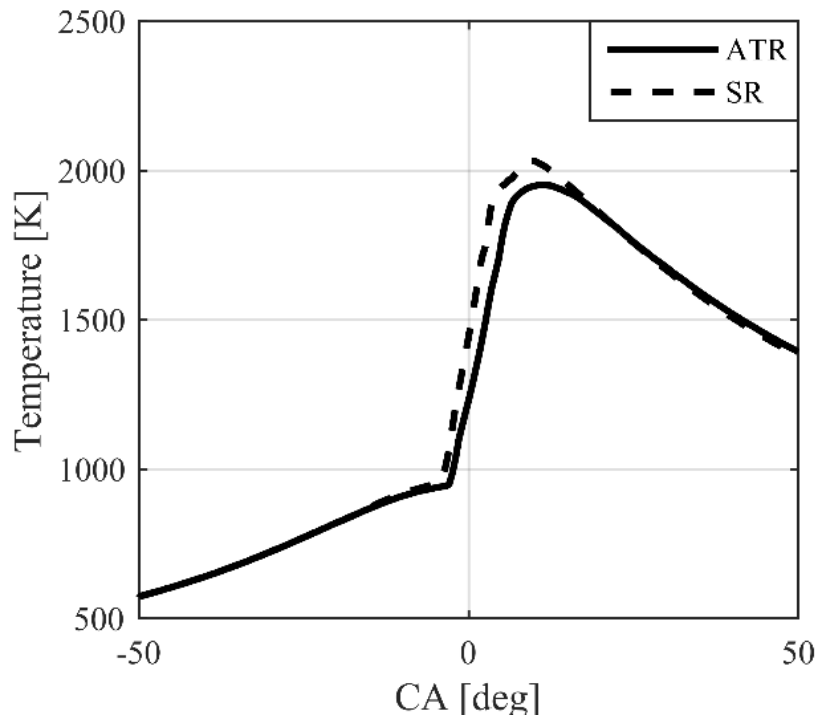

Figure 19. Bulk temperature comparison between ATR and SR 

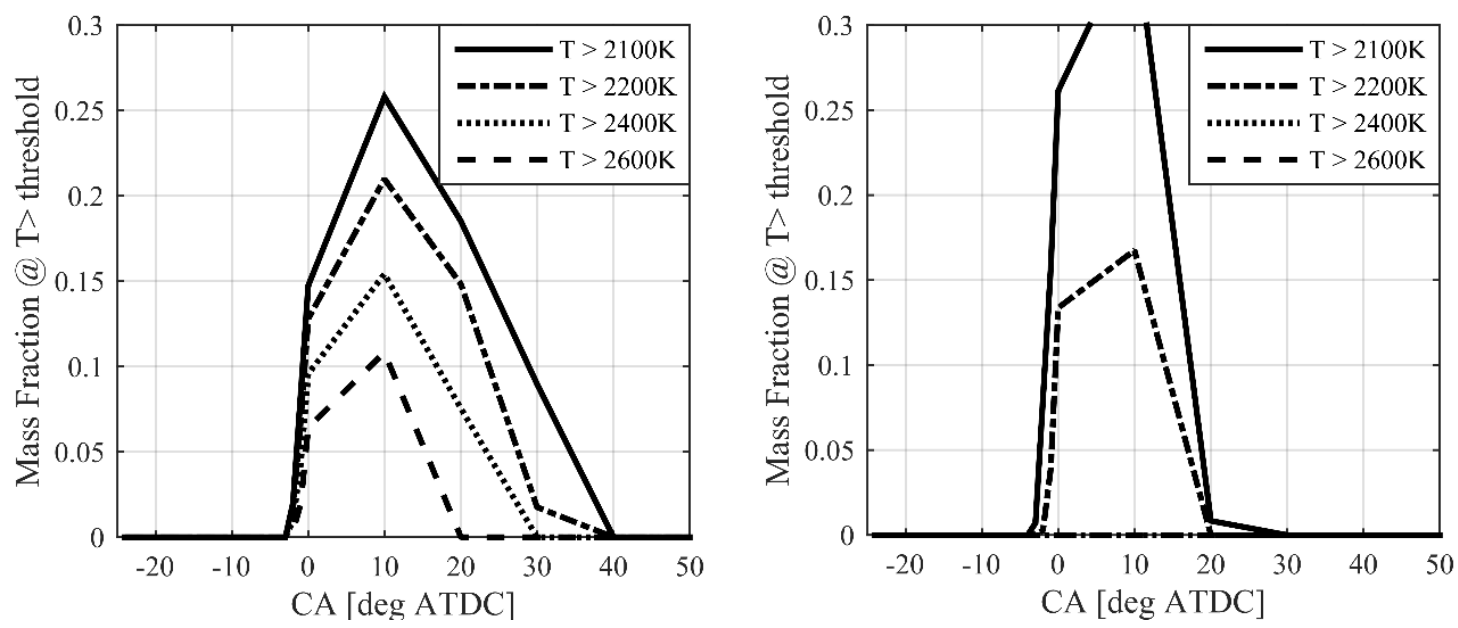

Figure 20. Mass fraction of fuel inside the cylinder above different temperature thresholds as a function of time, ATR (left) and SR (right). 


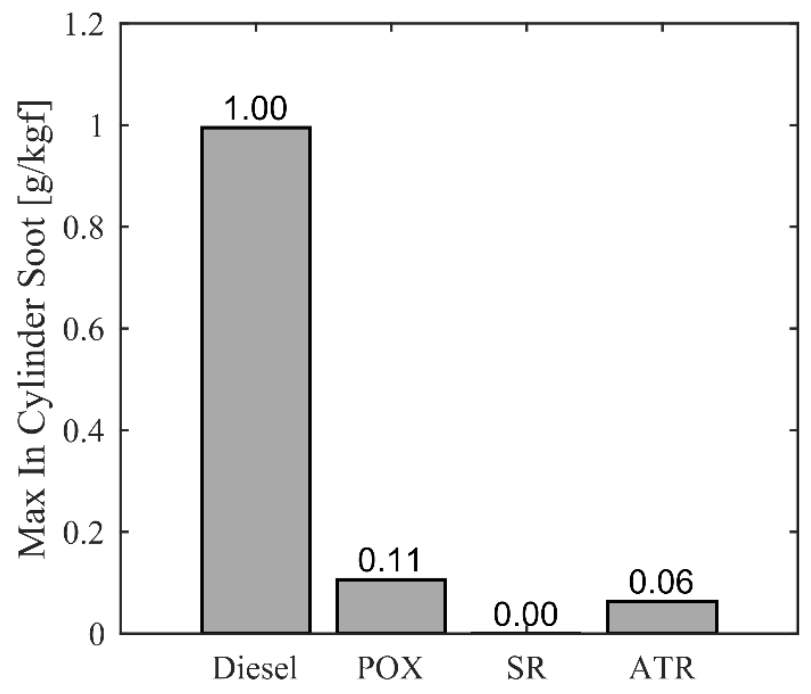

Figure 21. Maximum in-cylinder soot comparison for the optimal points 

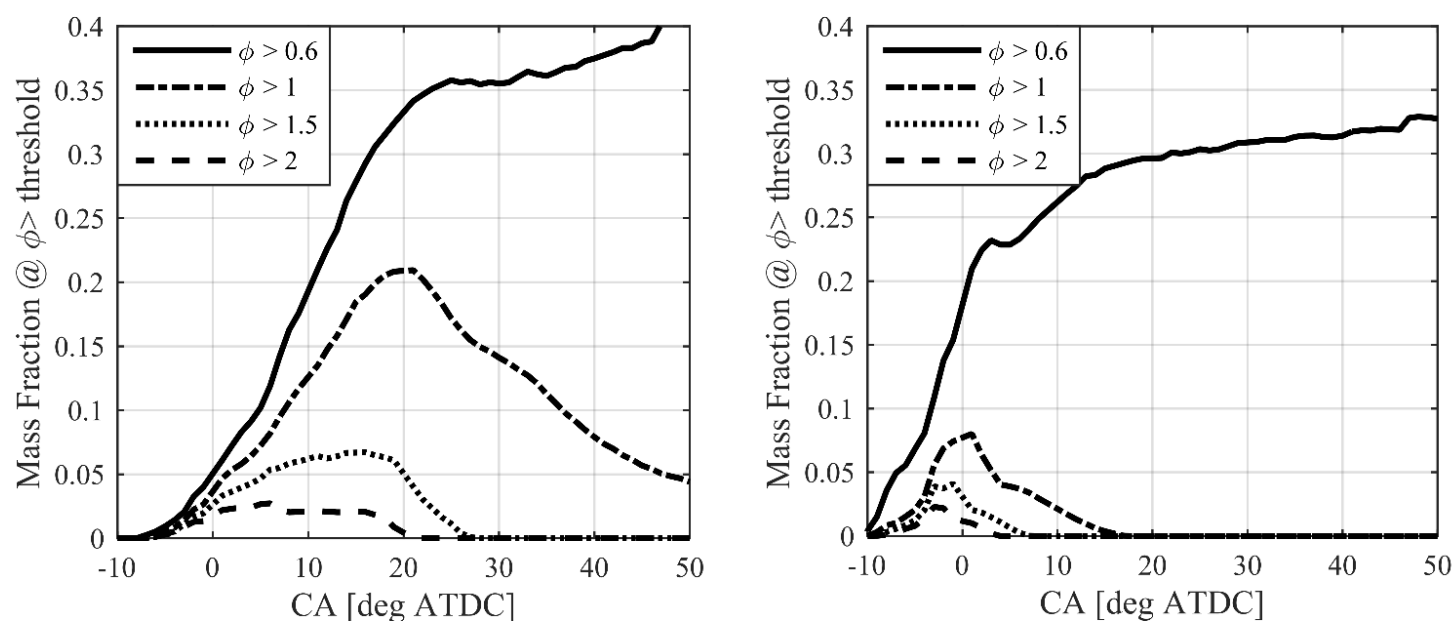

Figure 22. Mass fraction of fuel inside the cylinder above different equivalence ratio thresholds as a function of time, diesel (left) and POX (right). 

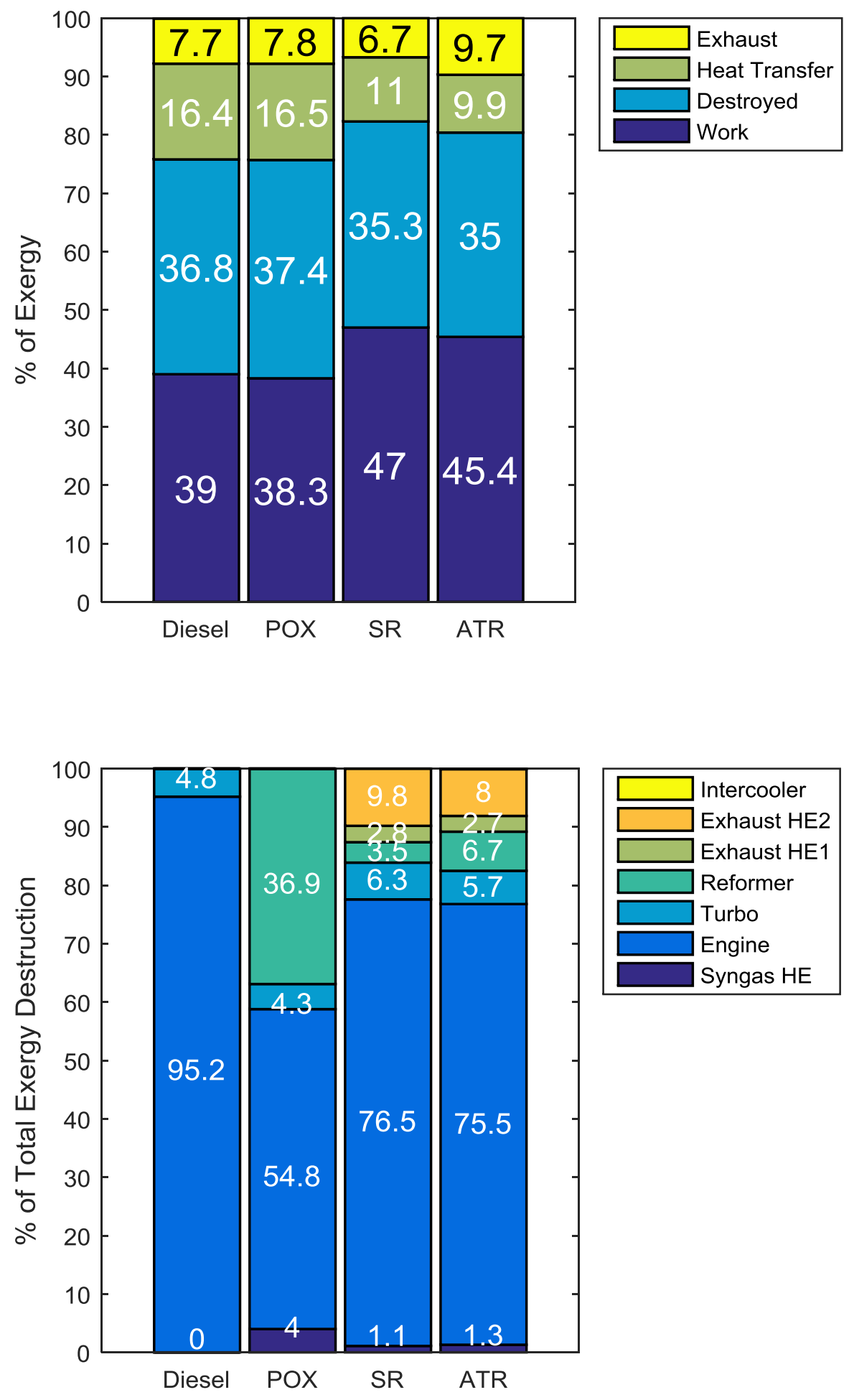

Figure 23. System exergy breakdown (top), exergy destruction breakdown for individual components (bottom) 


\section{References}

[1] Walker, N. R., Chuahy, F. D. F., and Reitz, R. D., "Comparison of diesel pilot ignition (DPI) and reactivity controlled compression ignition (RCCI) in a heavy-duty engine," Proc. ASME 2015 Internal Combustion Engine Division Fall Technical Conference, ICEF 2015.

[2] Wissink, M., and Reitz, R. D., 2015, "Direct Dual Fuel Stratification, a Path to Combine the Benefits of RCCI and PPC."

[3] Kokjohn, S., Hanson, R., Splitter, D., Kaddatz, J., and Reitz, R. D., 2011, "Fuel Reactivity Controlled Compression Ignition (RCCI) Combustion in Light- and Heavy-Duty Engines."

[4] Noehre, C., Andersson, M., Johansson, B., and Hultqvist, A., 2006, "Characterization of Partially Premixed Combustion," SAE International.

[5] Manente, V., Johansson, B., and Cannella, W., 2011, "Gasoline partially premixed combustion, the future of internal combustion engines?," International Journal of Engine Research, 12(3), pp. 194-208.

[6] Dec, J. E., Yang, Y., and Dronniou, N., 2011, "Boosted HCCI - Controlling Pressure-Rise Rates for Performance Improvements using Partial Fuel Stratification with Conventional Gasoline," SAE Int. J. Engines, 4(1), pp. 1169-1189.

[7] Kokjohn, S. L., Swor, T. A., Andrie, M. J., and Reitz, R. D., 2009, "Experiments and Modeling of Adaptive Injection Strategies (AIS) in Low Emissions Diesel Engines," SAE Int. J. Engines, 2(1), pp. 16-32.

[8] Wissink, M., and Reitz, R., 2016, "Exploring the Role of Reactivity Gradients in Direct Dual Fuel Stratification," SAE Int. J. Engines, 9(2).

[9] Kokjohn, S. L., Hanson, R. M., Splitter, D. A., and Reitz, R. D., 2009, "Experiments and Modeling of Dual-Fuel HCCI and PCCI Combustion Using In-Cylinder Fuel Blending," SAE Int. J. Engines, 2(2), pp. 24-39.

[10] Hanson, R. M., Kokjohn, S. L., Splitter, D. A., and Reitz, R. D., 2010, "An Experimental Investigation of Fuel Reactivity Controlled PCCI Combustion in a Heavy-Duty Engine," SAE Int. J. Engines, 3(1), pp. 700-716.

[11] Splitter, D., Hanson, R., Kokjohn, S., and Reitz, R. D., 2011, "Reactivity Controlled Compression Ignition (RCCI) Heavy-Duty Engine Operation at Mid-and High-Loads with Conventional and Alternative Fuels," SAE International.

[12] Kokjohn, S. L., and Reitz, R. D., 2008, "A Computational Investigation of Two-Stage Combustion in a Light-Duty Engine."

[13] Papagiannakis, R. G., Hountalas, D. T., Rakopoulos, C. D., and Rakopoulos, D. C., 2008, "Combustion and Performance Characteristics of a DI Diesel Engine Operating from Low to High Natural Gas Supplement Ratios at Various Operating Conditions," SAE International. [14] Splitter, D., Wissink, M., Kokjohn, S., and Reitz, R. D., 2012, "Effect of Compression Ratio and Piston Geometry on RCCI Load Limits and Efficiency," SAE International.

[15] Splitter, D., Martin, W., Hendricks, T., Ghandhi, J., and Reitz, R., "Comparison of RCCI, HCCI, and CDC Operation from Low to Full Load."

[16] Reitz, R. D., and Duraisamy, G., 2015, "Review of high efficiency and clean reactivity controlled compression ignition (RCCI) combustion in internal combustion engines," Progress in Energy and Combustion Science, 46, pp. 12-71.

[17] Splitter, D., Reitz, R. D., and Hanson, R., 2010, "High Efficiency, Low Emissions RCCI Combustion by Use of a Fuel Additive," SAE Int. J. Fuels Lubr., 3(2), pp. 742-756.

[18] Peng, X. D., 2012, "Analysis of the Thermal Efficiency Limit of the Steam Methane

Reforming Process," Industrial \& Engineering Chemistry Research, 51(50), pp. 16385-16392. 
[19] Sjöström, K., Eriksson, S., and Landqvist, G., 1981, "Onboard Hydrogen Generation for Hydrogen Injection into Internal Combustion Engines," SAE International.

[20] Jones, M. R., and Wyszynski, M. L., 1993, "Exhaust-Gas Reforming of Hydrocarbon Fuels," SAE International.

[21] Vernon, D. R., Jordan, E. A., Woolley, J. M., and Erickson, P. A., 2007, "The Potential for Exhaust Heat Recovery by Thermochemical Recuperation for Hydrogen Enriched Internal Combustion," Proceedings of the ASME Internal Combustion Engine Division, Fall Technical ConferenceCharleston, South Carolina, p. 9.

[22] Rakopoulos, C. D., and Giakoumis, E. G., 2006, "Second-law analyses applied to internal combustion engines operation," Progress in Energy and Combustion Science, 32(1), pp. 2-47. [23] Chakravarthy, V. K., Daw, C. S., Pihl, J. A., and Conklin, J. C., 2010, "Study of the Theoretical Potential of Thermochemical Exhaust Heat Recuperation for Internal Combustion Engines," Energy \& Fuels, 24(3), pp. 1529-1537.

[24] Szybist, J. P., Chakravathy, K., and Daw, C. S., 2012, "Analysis of the Impact of Selected Fuel Thermochemical Properties on Internal Combustion Engine Efficiency," Energy \& Fuels, 26(5), pp. 2798-2810.

[25] Lee, R. C., and Wimmer, D. B., 1968, "Exhaust Emission Abatement by Fuel Variations to Produce Lean Combustion," SAE International.

[26] Newkirk, M. S., and Abel, J. L., 1972, "The Boston Reformed Fuel Car," SAE International. [27] Martin, M. D., 1978, "Gaseous Automotive Fuels from Steam Reformed Liquid Hydrocarbons," SAE International.

[28] Houseman, J., and Cerini, D. J., 1974, "On-Board Hydrogen Generator for a Partial Hydrogen Injection Internal Combustion Engine," SAE International.

[29] Jones, M. R., "Feasibility Studies of the Exhaust Gas Reforming of Hydrocarbon and Alcohol Fuels," PhD thesis (Industrial/Technology Edition), University of Birmingham. [30] Cracknell, R. F., Kramer, G. J., and Vos, E., 2004, "Designing Fuels Compatible with Reformers and Internal Combustion Engines," SAE International.

[31] Posada, F., Bedick, C., Clark, N., Kozlov, A., Linck, M., Boulanov, D., and Pratapas, J., 2007, "Low Temperature Combustion with Thermo-Chemical Recuperation," SAE International. [32] Shudo, T., Shima, Y., and Fujii, T., 2009, "Production of dimethyl ether and hydrogen by methanol reforming for an HCCI engine system with waste heat recovery - Continuous control of fuel ignitability and utilization of exhaust gas heat," International Journal of Hydrogen Energy, 34(18), pp. 7638-7647.

[33] Tartakovsky, L., Baibikov, V., and Veinblat, M., 2013, "Comparative Performance Analysis of SI Engine Fed by Ethanol and Methanol Reforming Products," SAE International.

[34] Poran, A., Artoul, M., Sheintuch, M., and Tartakovsky, L., 2014, "Modeling Internal Combustion Engine with Thermo-Chemical Recuperation of the Waste Heat by Methanol Steam Reforming."

[35] Poran, A., and Tartakovsky, L., 2015, "Energy efficiency of a direct-injection internal combustion engine with high-pressure methanol steam reforming," Energy, 88, pp. 506-514. [36] Fennell, D., Herreros, J., and Tsolakis, A., 2014, "Improving gasoline direct injection (GDI) engine efficiency and emissions with hydrogen from exhaust gas fuel reforming," International Journal of Hydrogen Energy, 39(10), pp. 5153-5162.

[37] Fennell, D., Herreros, J., Tsolakis, A., Cockle, K., Pignon, J., and Millington, P., 2015, "Thermochemical recovery technology for improved modern engine fuel economy - part 1: analysis of a prototype exhaust gas fuel reformer," RSC Advances, 5(44), pp. 35252-35261. 
[38] Ra, Y., and Reitz, R. D., 2003, "The application of a multicomponent droplet vaporization model to gasoline direct injection engines," International Journal of Engine Research, 4(3), pp. 193-218.

[39] Abani, N., Kokjohn, S., Park, S. W., Bergin, M., Munnannur, A., Ning, W., Sun, Y., and Reitz, R. D., 2008, "An Improved Spray Model for Reducing Numerical Parameter Dependencies in Diesel Engine CFD Simulations," SAE International. [40] Beale, J. C., and Reitz, R. D., 1999, "MODELING SPRAY ATOMIZATION WITH THE KELVIN-HELMHOLTZ/RAYLEIGH-TAYLOR HYBRID MODEL," 9(6), pp. 623-650. [41] Han, Z., and Reitz, R. D., 1995, "Turbulence Modeling of Internal Combustion Engines Using RNG $\kappa-\varepsilon$ Models," Combustion Science and Technology, 106(4-6), pp. 267-295.

[42] Munnannur, A., and Reitz, R. D., 2007, "A new predictive model for fragmenting and nonfragmenting binary droplet collisions," International Journal of Multiphase Flow, 33(8), pp. 873896.

[43] O'Rourke, P. J., and Amsden, A. A., 2000, "A Spray/Wall Interaction Submodel for the KIVA-3 Wall Film Model," SAE International.

[44] Perini, F., Galligani, E., and Reitz, R. D., 2012, "An Analytical Jacobian Approach to Sparse Reaction Kinetics for Computationally Efficient Combustion Modeling with Large Reaction Mechanisms," Energy \& Fuels, 26(8), pp. 4804-4822.

[45] Wang, H., Jiao, Q., Yao, M., Yang, B., Qiu, L., and Reitz, R. D., 2013, "Development of an n-heptane/toluene/polyaromatic hydrocarbon mechanism and its application for combustion and soot prediction," International Journal of Engine Research, 14(5), pp. 434-451.

[46] Hiroyasu, H., and Kadota, T., 1976, "Models for Combustion and Formation of Nitric Oxide and Soot in Direct Injection Diesel Engines," SAE International.

[47] Liu, Y., Tao, F., Foster, D. E., and Reitz, R. D., 2005, "Application of A Multiple-Step Phenomenological Soot Model to HSDI Diesel Multiple Injection Modeling," SAE International. [48] Sun, Y., 2007, "Diesel combustion optimization and emissions reduction using adaptive injection strategies (AIS) with improved numerical models," 2007.

[49] DG, G., 2015, "Cantera: An Object-oriented Software Toolkit for Chemical Kinetics, Thermodynamics, and Transport Processes," M. HK, ed.

[50] Parmar, R. D., Kundu, A., and Karan, K., 2009, "Thermodynamic analysis of diesel reforming process: Mapping of carbon formation boundary and representative independent reactions," Journal of Power Sources, 194(2), pp. 1007-1020.

[51] Bell, I. H., Wronski, J., Quoilin, S., and Lemort, V., 2014, "Pure and Pseudo-pure Fluid Thermophysical Property Evaluation and the Open-Source Thermophysical Property Library CoolProp," Industrial \& Engineering Chemistry Research, 53(6), pp. 2498-2508.

[52] Li, Y.-R., Wang, J.-N., and Du, M.-T., 2012, "Influence of coupled pinch point temperature difference and evaporation temperature on performance of organic Rankine cycle," Energy, 42(1), pp. 503-509.

[53] Wu, S.-Y., Zhou, S.-M., Xiao, L., Li, Y.-R., Liu, C., and Xu, J.-L., 2014, "Determining the optimal pinch point temperature difference of evaporator for waste heat recovery," Journal of the Energy Institute, 87(2), pp. 140-151.

[54] Horlock, J. H., 1995, "Combined Power Plants—Past, Present, and Future," Journal of Engineering for Gas Turbines and Power, 117(4), pp. 608-616.

[55] Stepanov, V. S., 1995, "Chemical energies and exergies of fuels," Energy, 20(3), pp. 235242. 
[56] Lin, Y., and Zhang, H. H., "Component selection and smoothing in multivariate nonparametric regression," pp. Institute of Statistics Mimeo Series 2556, NUCS, 2003.

[57] Klos, D. T. a., 2015, "Investigations of low temperature combustion (LTC) engine design and combustion instability," MS Thesis, Mechanical Engineering, University of WisconsinMadison, Madison, WI, 2015.

[58] Dal Forno Chuahy, F., Ra, Y., and Kokjohn, S., 2015, "Effects of the Direct-Injected Fuel Physical Properties Under Early and Late Reactivity Controlled Compression

Ignition Combustion," 27th Annual Conference on Liquid Atomization and Spray Systems, Raleigh, NC.

[59] Caton, J. A., 2000, "On the destruction of availability (exergy) due to combustion processes - with specific application to internal-combustion engines," Energy, 25(11), pp. 1097-1117.

[60] Nishida, K., Takagi, T., and Kinoshita, S., 2002, "Analysis of entropy generation and exergy loss during combustion," Proceedings of the Combustion Institute, 29(1), pp. 869-874.

[61] Som, S. K., and Datta, A., 2008, "Thermodynamic irreversibilities and exergy balance in combustion processes," Progress in Energy and Combustion Science, 34(3), pp. 351-376.

[62] Dempsey, A. B., 2013, "Dual-fuel Reactivity Controlled Compression Ignition (RCCI) with alternative fuels," Ph.D Thesis, Mechanical Engineering, University of Wisconsin Madison. 


\section{Appendix}

Table 8. Surface temperatures used for the $2^{\text {nd }}$ law analysis

\begin{tabular}{|l|c|}
\hline & Value [K] \\
\hline Intercooler & 350 \\
\hline Engine & 600 \\
\hline Reformer & 800 \\
\hline Recovery Heat Exchangers & 500 \\
\hline Syngas Heat Exchanger & 500 \\
\hline
\end{tabular}

Table 9. Summary of thermodynamic conditions for the POX system

\begin{tabular}{|c|c|c|c|c|c|}
\hline & $\mathrm{m}[\mathrm{g} /$ cycle $]$ & $\mathrm{P}[\mathrm{Pa}]$ & $\mathrm{T}[\mathrm{K}]$ & $\mathrm{h}[\mathrm{J} / \mathrm{kg}]$ & $\mathrm{s}[\mathrm{J} / \mathrm{kgK}]$ \\
\hline 1 & 3.29 & 96000 & 300 & 1873.79 & 7059 \\
\hline 2 & 3.29 & 151793 & 364 & 66728.2 & 7124.4 \\
\hline 3 & 2.78 & 151793 & 313 & 52161.7 & 7083.3 \\
\hline 4 & 3.41 & 161366 & 853 & $-1.049 \mathrm{e}+06$ & 8246.9 \\
\hline 5 & 3.41 & 112000 & 800 & $-1.11156 \mathrm{e}+06$ & 8273.8 \\
\hline 6 & 0 & 0 & 0 & 0 & 0 \\
\hline 7 & 0 & 0 & 0 & 0 & 0 \\
\hline 8 & 0.018 & 101325 & 300 & $-2.06296 \mathrm{e}+06$ & 2902 \\
\hline 9 & 0.102 & 101325 & 300 & $-2.06296 \mathrm{e}+06$ & 2902 \\
\hline 10 & 0.102 & 101325 & 300 & $-2.06296 \mathrm{e}+06$ & 2902 \\
\hline 11 & 0 & 0 & 0 & 0 & 0 \\
\hline 12 & 0 & 0 & 0 & 0 & 0 \\
\hline 13 & 0.616 & 151793 & 1116 & -260629 & 10736 \\
\hline 14 & 0.613 & 151793 & 300 & $-1.35429 \mathrm{e}+06$ & 8875.8 \\
\hline 15 & 0 & 151793 & $1.12 \mathrm{e}+03$ & $1.19657 \mathrm{e}+06$ & 2239.4 \\
\hline 16 & 0.00355 & 151793 & 373 & $-1.55156 \mathrm{e}+07$ & 4825.2 \\
\hline
\end{tabular}


Table 10. Summary of thermodynamic conditions for the ATR system

\begin{tabular}{|c|c|c|c|c|c|}
\hline & $\begin{array}{c}\mathrm{m} \\
{[\mathrm{g} / \text { cycle }]}\end{array}$ & $\mathrm{P}[\mathrm{Pa}]$ & $\mathrm{T}[\mathrm{K}]$ & $\mathrm{h}[\mathrm{J} / \mathrm{kg}]$ & $\mathrm{s}[\mathrm{J} / \mathrm{kgK}]$ \\
\hline 1 & 3.3 & 96000 & 300 & 1873.79 & 7059 \\
\hline 2 & 3.3 & 156353 & 369 & 71211.3 & 7128.2 \\
\hline 3 & 3.26 & 156353 & 313 & 52154.3 & 7074.8 \\
\hline 4 & 3.47 & 165210 & 831 & -986909 & 8350.7 \\
\hline 5 & 3.47 & 112000 & 775 & $-1.05275 \mathrm{e}+06$ & 8378.8 \\
\hline 6 & 3.47 & 106000 & 747 & $-1.0861 \mathrm{e}+06$ & 8350.4 \\
\hline 7 & 3.47 & 101325 & 668 & $-1.17752 \mathrm{e}+06$ & 8234.1 \\
\hline 8 & 0.0137 & 101325 & 300 & $-2.06296 \mathrm{e}+06$ & 2902 \\
\hline 9 & 0.0774 & 101325 & 300 & $-2.06296 \mathrm{e}+06$ & 2902 \\
\hline 10 & 0.0774 & 101325 & 746 & -574421 & 6139.5 \\
\hline 11 & 0.0983 & 101325 & 300 & $-1.58573 \mathrm{e}+07$ & 3912 \\
\hline 12 & 0.0983 & 101325 & 718 & $-1.25981 \mathrm{e}+07$ & 12747 \\
\hline 13 & 0.213 & 156353 & 1050 & $-2.19535 \mathrm{e}+06$ & 15945 \\
\hline 14 & 0.2 & 156353 & 300 & $-3.41561 \mathrm{e}+06$ & 12859 \\
\hline 15 & 0.00094 & 156353 & $1.05 \mathrm{e}+03$ & $1.07452 \mathrm{e}+06$ & 2126.7 \\
\hline 16 & 0.0131 & 156353 & 373 & $-1.54979 \mathrm{e}+07$ & 4825.2 \\
\hline
\end{tabular}


Table 11. Summary of thermodynamic conditions for the SR system

\begin{tabular}{|c|c|c|c|c|c|}
\hline & $\mathrm{m}[\mathrm{g} / \mathrm{cycle}]$ & $\mathrm{P}[\mathrm{Pa}]$ & $\mathrm{T}[\mathrm{K}]$ & $\mathrm{h}[\mathrm{J} / \mathrm{kg}]$ & $\mathrm{s}[\mathrm{J} / \mathrm{kgK}]$ \\
\hline 1 & 3.34 & 96000 & 300 & 1873.79 & 7059 \\
\hline 2 & 3.34 & 160912 & 371 & 75601.5 & 7131.8 \\
\hline 3 & 3.34 & 160912 & 313 & 52147 & 7066.5 \\
\hline 4 & 3.53 & 170189 & 817 & $-1.00139 \mathrm{e}+06$ & 8349.8 \\
\hline 5 & 3.53 & 112000 & 757 & $-1.07118 \mathrm{e}+06$ & 8379.8 \\
\hline 6 & 3.53 & 106000 & 729 & $-1.10451 \mathrm{e}+06$ & 8350.4 \\
\hline 7 & 3.53 & 101325 & 631 & $-1.21685 \mathrm{e}+06$ & 8197.2 \\
\hline 8 & 0.0034 & 101325 & 300 & $-2.06296 \mathrm{e}+06$ & 2902 \\
\hline 9 & 0.0816 & 101325 & 300 & $-2.06296 \mathrm{e}+06$ & 2902 \\
\hline 10 & 0.0816 & 101325 & 728 & -630706 & 6064.1 \\
\hline 11 & 0.124 & 101325 & 300 & $-1.58573 \mathrm{e}+07$ & 3912 \\
\hline 12 & 0.124 & 101325 & 700 & $-1.26351 \mathrm{e}+07$ & 12700 \\
\hline 13 & 0.206 & 160912 & 1050 & $-2.72466 \mathrm{e}+06$ & 17478 \\
\hline 14 & 0.189 & 160912 & 300 & $-3.99546 \mathrm{e}+06$ & 14090 \\
\hline 15 & 0 & 160912 & $1.05 \mathrm{e}+03$ & $1.0745 \mathrm{e}+06$ & 2126.7 \\
\hline 16 & 0.017 & 160912 & 373 & $-1.55487 \mathrm{e}+07$ & 4825.2 \\
\hline
\end{tabular}

Table 12. Summary of thermodynamic conditions for the diesel system

\begin{tabular}{|c|c|c|c|c|c|}
\hline & $\mathrm{m}[\mathrm{g} /$ cycle $]$ & $\mathrm{P}[\mathrm{Pa}]$ & $\mathrm{T}[\mathrm{K}]$ & $\mathrm{h}[\mathrm{J} / \mathrm{kg}]$ & $\mathrm{s}[\mathrm{J} / \mathrm{kgK}]$ \\
\hline 1 & 3.6 & 96000 & 300 & 1873.79 & 7059 \\
\hline 2 & 3.6 & 151793 & 364 & 66728.2 & 7124.4 \\
\hline 3 & 3.6 & 151793 & 313 & 52161.7 & 7083.3 \\
\hline 4 & 3.72 & 161607 & 850 & -946159 & 8247.1 \\
\hline 5 & 3.72 & 112000 & 796 & $-1.0089 \mathrm{e}+06$ & 8247.1 \\
\hline 6 & 0 & 0 & 0 & 0 & 0 \\
\hline 7 & 0 & 0 & 0 & 0 & 0 \\
\hline 8 & 0.12 & 101325 & 300 & $-2.06296 \mathrm{e}+06$ & 2902 \\
\hline 9 & 0 & 0 & 0 & 0 & 0 \\
\hline 10 & 0 & 0 & 0 & 0 & 0 \\
\hline 11 & 0 & 0 & 0 & 0 & 0 \\
\hline 12 & 0 & 0 & 0 & 0 & 0 \\
\hline 13 & 0 & 0 & 0 & 0 & 0 \\
\hline 14 & 0 & 0 & 0 & 0 & \\
\hline
\end{tabular}

